\title{
LLNL SFA FY11 Program Management and Performance Report: Environmental Transport of Plutonium
}

A. B. Kersting, M. Zavarin, B. A. Powell, D. Moser, S. A. Carroll, R. Maxwell, Z. Dai, R. Williams, S. Tumey, P. Zhao, R. Tinnacher, P. Huang, R. Kips, H. Mason, J. Begg, J. Fisher, L. Simpkins, T. Zimmerman, J. Jablonski, M. Snow

July 5,2011 
This document was prepared as an account of work sponsored by an agency of the United States government. Neither the United States government nor Lawrence Livermore National Security, LLC, nor any of their employees makes any warranty, expressed or implied, or assumes any legal liability or responsibility for the accuracy, completeness, or usefulness of any information, apparatus, product, or process disclosed, or represents that its use would not infringe privately owned rights. Reference herein to any specific commercial product, process, or service by trade name, trademark, manufacturer, or otherwise does not necessarily constitute or imply its endorsement, recommendation, or favoring by the United States government or Lawrence Livermore National Security, LLC. The views and opinions of authors expressed herein do not necessarily state or reflect those of the United States government or Lawrence Livermore National Security, LLC, and shall not be used for advertising or product endorsement purposes.

This work performed under the auspices of the U.S. Department of Energy by Lawrence Livermore National Laboratory under Contract DE-AC52-07NA27344. 
LLNL-TR-490259

\section{LLNL SFA FY11 Program Management and Performance Report:}

\section{Environmental Transport of Plutonium: \\ Biogeochemical Processes at Femtomolar Concentrations and Nanometer Scales}

Laboratory Research Manager:

Annie Kersting

Director, Glenn T. Seaborg Institute

Physical \& Life Sciences Directorate

Lawrence Livermore National Laboratory

L-231, Livermore CA 94550

925 432-2228

Kersting1@LLNL.gov

Laboratory Lead Scientist:

Mavrik Zavarin

Collaborators:

Brian Powell ${ }^{2}$, Duane Moser ${ }^{3}$, Susan Carroll ${ }^{1}$, Robert Maxwell ${ }^{1}$, Zurong Dai ${ }^{1}$, Ross Williams ${ }^{1}$,

Scott Tumey ${ }^{1}$, Pihong Zhao ${ }^{1}$, Ruth Tinnacher ${ }^{1}$, Patrick Huang ${ }^{1}$, Ruth Kips ${ }^{1}$, Harris Mason ${ }^{1}$, James

Begg $^{1}$, Jen Fisher ${ }^{3}$, Laura Simpkin ${ }^{2}$, Trevor Zimmerman ${ }^{2}$, Joseph Jablonski ${ }^{2}$ Matthew Snow ${ }^{1}$.

${ }^{1}$ Lawrence Livermore National Laboratory, ${ }^{2}$ Clemson University, ${ }^{3}$ Desert Research Institute 


\section{TABLE of CONTENTS}

1. Program Overview 1

2. Scientific Objectives 1

3. Program Structure 2

4. Performance Milestones and Metrics 3

4.a Review of Scientific Progress 4

4.a.i Brief Review of Scientific Progress 4

Program Element A: Binary Sorption to High-Affinity Surface Sites 4

Program Element B: Stabilization of Pu Surface Complexes on Mineral Colloids by Natural Organic Matter 9

Program Element C: Surface Precipitation of Pu Colloids: Experimental and Natural Nanocolloids 14

$\begin{array}{ll}\text { Program Element D: Co-precipitation with Altered Colloids } & 17\end{array}$

Program Element E: Direct and Indirect Microbial Interactions with $\mathrm{Pu}$ and Colloids 19

4.a.ii Scientific Highlights $\quad 21$

4.a.iii Summary of Publications 22

$\begin{array}{lll}\text { 4.b } & \text { Future Scientific Goals } & 23\end{array}$

4.c New Scientific Results 23

4.d Collaborative Research Activities 23

5. Staffing and Budget Summary 24

5.a Funding Allocation by Program Element and Individual Researchers $\quad 24$

5.a.i Present Funding 24

5.b Funding Allocation to External Collaborators $\quad 24$

$\begin{array}{lll}\text { 5.c } & \text { Personnel Actions } & 24\end{array}$

$\begin{array}{lll}\text { 5.d National Laboratory Investments } & 24\end{array}$

$\begin{array}{lll}\text { 5.e Capital Equipment Needs } & 25\end{array}$

6. References 26 


\section{Program Overview}

The major challenge in predicting the mobility and transport of plutonium $(\mathrm{Pu})$ is determining the dominant geochemical processes that control its behavior in the subsurface. The reaction chemistry of $\mathrm{Pu}$ (i.e., aqueous speciation, solubility, sorptivity, redox chemistry, and affinity for colloidal particles, both abiotic and microbially mediated) is particularly complicated. It is generally thought that due to its low solubility and high sorptivity, Pu migration in the environment occurs only when facilitated by transport on particulate matter (i.e., colloidal particles). Despite the recognized importance of colloid-facilitated transport of $\mathrm{Pu}$, very little is known about the geochemical and biochemical mechanisms controlling Pu-colloid formation and association, particularly at femtomolar Pu concentrations observed at DOE sites.

Reactive transport models that address geochemical processes occurring at the mineral-water interface are still in their infancy for multi-phase systems (U.S. DEPARTMENT OF ENERGY, 2007). Generally, existing transport models have ignored the coupled factors of redox chemistry and microbial activity and have relied on empirical equilibrium or rate-limited distribution coefficient $\left(\mathrm{K}_{\mathrm{d}}\right)$ models to address actinide retardation and colloidfacilitated transport (e.g., Glynn, 2003; Pickett, 2005; Tien and Jen, 2007). Recent experimental data from Powell and others (Kaplan et al., 2004; Powell et al., 2005; Kaplan et al., 2006; Demirkanli et al., 2008) that these simplified models cannot adequately predict $\mathrm{Pu}$ transport because they do not capture the coupled processes controlling Pu sorption and desorption.

This 5-year program is designed to test the important biogeochemical processes governing colloid-facilitated $\mathrm{Pu}$ transport in the field. We hypothesize that biogeochemical processes operating under low $\left(10^{-9}-10^{-16} \mathrm{~mol} / \mathrm{L}\right)$, environmentally relevant, concentrations are fundamentally different from those operating in simple, binarysystem laboratory experiments conducted at high $\mathrm{Pu}$ concentrations $\left(10^{-4}-10^{-9} \mathrm{~mol} / \mathrm{L}\right)$. At environmentally relevant concentrations, $\mathrm{Pu}$ will be controlled by one or more of the following processes:

- $\quad$ binary sorption to low-site-density, high-affinity colloid surface sites (e.g., surface defects),

- $\quad$ stabilization of Pu surface complexes on mineral colloids by natural organic matter coatings,

- $\quad$ surface precipitation of Pu polymers: experimental and natural nano-colloids,

- $\quad$ co-precipitation with colloids as a result of mineral alteration, and

- $\quad$ direct and indirect microbial interactions with $\mathrm{Pu}$ and colloids.

Our hypothesis is being tested by selectively examining each process separately as a function of concentration and then evaluating its potential role in Pu transport. Laboratory results are being compared to field samples taken from contaminated sites (NTS, RFETS, the Hanford Reservation and Tomsk, Russia) where Pu-containing colloids/particles will be and characterized. The processes listed above form the basis for 5 Program Elements, each with its own hypothesis-driven research program. However, each Program Element includes tasks that integrate aspects of this research plan to address our central hypothesis. Program Elements include computational chemistry studies, controlled laboratory experiments, geochemical modeling, and field sample characterization efforts that address length scales from the atomic to the field scale.

\section{Scientific Objectives}

The objective of this science program is the identification and quantification of the biogeochemical processes that control the fate and transport of $\mathrm{Pu}$ at picomolar to attomolar $\left(10^{-12}-10^{-18} \mathrm{~mol} / \mathrm{L}\right)$ concentrations. We are investigating the roles of mineral surface defects, ternary complexes, polymerization, co-precipitation/surface alteration, as well as direct and indirect microbial interactions on the affinity and sorption/desorption rates of Pu. With the use of unique state-of-the-art facilities at LLNL such as the accelerator mass spectrometer (AMS), a NuPlasma HR IsoProbe mass spectrometer (MC-ICPMS), the Transmission Electron Microscope (TEM), and the nano-secondary ion mass spectrometer (NanoSIMS), we are conducting laboratory experiments on colloids at environmentally relevant concentrations. A primary goal of this program is to provide the DOE with the scientific basis to support decisions for the remediation and long-term stewardship of legacy sites. 


\section{Program Structure}

Dr. Kersting is the program manager and point of contact for this program. She is also Director of the LLNL branch of the Glenn T. Seaborg Institute (Seaborg Institute) and reports directly to the Associate Director of the Physical \& Life Sciences (PLS) Directorate, Bill Goldstein. Henry Shaw is the point-of-contact for LLNL's, BER Programs and is the Chief Scientist for PLS reporting directly to Bill Goldstein. This SFA program is managed through the Seaborg Institute and is aligned with the Seaborg Institute's research focus on environmental radiochemistry, nuclear forensics and super heavy element discovery.

Dr. Kersting communicates BER program needs to both the Lead Scientist, Dr. Zavarin, and Program Element leads, coordinates program execution, insures financial responsibility in spending, planning, and program direction. Monthly program meetings/teleconferences with all staff members leads will serve to communicate progress and ensure that the program goals are being met. Each Program Element has a lead scientist that reports to both the SFA manager (Dr. Kersting) and lead scientist (Dr. Zavarin). Dr. Kersting reports to both LLNL senior management and BER (Arthur Katz). Dr. Zavarin ensures that Program Element efforts at LLNL and collaborating institutions are aligned with the research outlined.

The majority of the experimental work (Program Elements A, C, and D) is led by LLNL scientists under the supervision of Dr. Zavarin in his environmental radiochemistry laboratories. Program Element B and E leads and their post-docs/graduate students have access to LLNL through the Laboratory's Visiting Scientist Program. The sorption/desorption experiments in Program Element B (B. Powell lead) is a coordinated effort between Clemson University and LLNL. The microbial work in Program Element E (D. Moser lead) is carried out at the Desert Research Institute and LLNL. Characterization and isolation of microbial populations in Pucontaminated groundwater at the NTS are coordinated through external programs (e.g., UGTA). Groundwater and sediment sample collection at other field sites is being coordinated through targeted collaborations (Hanford (A. Felmy); Tomsk, Russia (S. Kalmykov).

In addition to the roles of Dr. Kersting and Dr. Zavarin discussed above, each team member is indentified below.

Annie Kersting - Director of the Glenn T. Seaborg Institute at LLNL, which conducts research on environmental radiochemistry and nuclear forensics. She also oversees both the postdoc ( $\sim 90$ postdocs) and a nuclear forensics summer student program ( 10- summer students). Her research focuses on actinide transport in the subsurface. Dr. Kersting is the program manager for this SFA and is the lead on Program Element C: Surface precipitation of Pu polymers and field samples. She co-supervises postdocs Ruth Tinnacher, Ruth Kips and James Begg (FY10 new hire), and coordinates summer students.

Mavrik Zavarin - LLNL Project manager for the Underground Test Area (UGTA) program responsible for identifying the extent of radiologic contamination at the NTS. Dr. Zavarin has been involved in experimental and modeling studies of radionuclide chemistry at the mineral-water interface, mineral dissolution/precipitation kinetics, colloid-facilitated transport, and radionuclide reactive transport modeling. Dr. Zavarin is the Lead Scientist, is responsible overseeing Program Elements A-E and also the lead for Program Element A: Binary sorption to lowdensity high affinity surface sites. Dr. Zavarin coordinates NTS field operations with UGTA for program Element E: microbial interactions. He co-supervises postdocs Ruth Tinnacher, and James Begg (FY10 new hire).

Brian Powell—Assistant professor, Clemson University, radiochemist. Prof. Powell's research focuses on understanding and quantifying the rates and mechanisms of actinide interactions with natural soils and synthetic minerals. He continues to be involved with experimental and modeling studies of long-term Pu vadose zone transport at the Savannah River Site. Prof. Powell will coordinate activities between Clemson and LLNL and supervises graduate students that carry out graduate thesis work on this project.

Duane Moser-Microbial Ecologist at the Desert Research Institute. Dr. Moser has over 15 years of experience in monitoring microorganisms and their activities in the environment with an emphasis on the deep subsurface, aquatic systems and bioremediation. Moser is experienced in molecular- and cultivation-based approaches for microbial detection and provides a full complement of microbiological tools and analyses for the team, both field and laboratory. He supervises postdoc, Jen Fisher.

Pihong Zhao Radiochemist with over 16 years experience in environmental radiochemistry, waste form, thermodynamic data measurements for actinides and development of actinides separations. Dr. Zhao serves as lab manager for the program and has daily oversight responsibility over post-doc and student laboratory activities as part of this SFA. 
Robert Maxwell—Chemist with expertise application of nuclear magnetic resonance methods to the study of the structure and dynamics of materials, polymer aging and degradation, dissolution kinetics of silica polymorphs, and organic-inorganic composite materials.

Susan Carroll-Geochemist who has conducted and published research for a variety of rock-water systems focusing on experimental surface chemistry, mineral kinetics, mobility of metal and radioactive contaminants, and geologic $\mathrm{CO}_{2}$ sequestration. She supervises postdoc Harris Mason.

Zurong Dai-Physicist, materials scientist at LLNL. Dr. Dai has more than 20 years experience in structural characterization of natural and man-made materials by using TEM. His research focuses on crystal growth and crystallography, nano-materials synthesis and characterization, experimental measurement of electronic structure and optical properties of materials. Dr. Dai will be responsible for the TEM analyses.

Ross Williams - Isotope geochemist at LLNL, Dr. Williams is the laboratory manager for the Chemical Science Division's ICP-MS Facility and chief scientists for the multi-collector NuPlasma HR IsoProbe ICPMS. Dr. Williams sets the standard for isotope ratio mass spectrometry in the DOE complex. He has more than 20 years of experience in actinide radiochemistry and metrology. Dr. Williams will be responsible for measurement and interpretation of ICPMS measurements.

Scott Tumey-Radioanalytical chemist at the LLNL Center for Accelerator Mass Spectrometry (CAMS). Dr. Tumey is a key member of the heavy-isotope group at CAMS and has played a central roe in developing AMS measurement capabilities for actinides. Dr. Tumey will oversee the preparation and measurement of samples by AMS, and helps design laboratory experiments so that they adequately reflect the sample requirements of AMS.

Ruth Tinnacher-Postdoctoral fellow at LLNL. Dr. Tinnacher's research focuses on parameters and processes that control the sorption, remobilization and transport behavior of actinides in the environment such as organic and inorganic colloids and metal sorption/desorption kinetics. She has several years of experience in conducting lab-scale experiments with uranium, $\mathrm{Pu}$ and various organic matter fractions using batch, static column and advective column systems. Dr. Tinnacher will conduct sorption/desorption experiments.

Ruth Kips - Postdoctoral fellow at LLNL. Dr. Kips' research focuses on nuclear safeguards and the application of micro-analytical tools to the analysis of sub-micrometer-sized actinide particles to determine their morphological, isotopic, and compositional characteristics using electron microscopy, X-ray diffraction, ICP-MS, and NanoSIMS. She will use the NanoSIMS to characterize field and experimentally derived colloids.

Harris Mason-Postdoctoral fellow at LLNL. Dr. Mason's research focuses on applying NMR spectroscopic techniques to investigate metal sorption reactions at the mineral/water interface. He will use these methods to investigate how $\mathrm{Pu}$ behaves at the silica interface.

Jen Fisher - Postdoctoral associate at the Desert Research Institute. Dr. Fisher's research focuses on the microbial ecology of extreme environments and the interaction of microorganisms with toxic metal(loid)s. She will be isolating and characterizing metal-reducing and exopolysaccharide-producing bacteria from the Nevada Test Site and using these organisms in sorption experiments with $\mathrm{Pu}$.

James Begg - Postdoctoral fellow at LLNL. Dr Begg's expertise is in environmental radiochemistry and his research focuses on actinide sorption on inorganic phases, specifically Fe-oxides and clays.

\section{Performance Milestones and Metrics}

Table 4.1 shows the task plan schedule for five years for each of the five Program Elements. Each Program Elements is sub-divided into Tasks. However, all activities are closely integrated and as such, timing of specific experiments, especially as proposed in out years, may be modified. Blue demarcations show the original planned schedule and the green shows where we have deviated for the original plan. The accomplishments and metrics for each Program Element will be summarized below.

Table 4.1 Five year task plan subdivided into five Program Elements (A-E). The blue is the original plan, the green denotes where some projects were started earlier than originally planned, the lightest blue shows where projects have been delayed. 

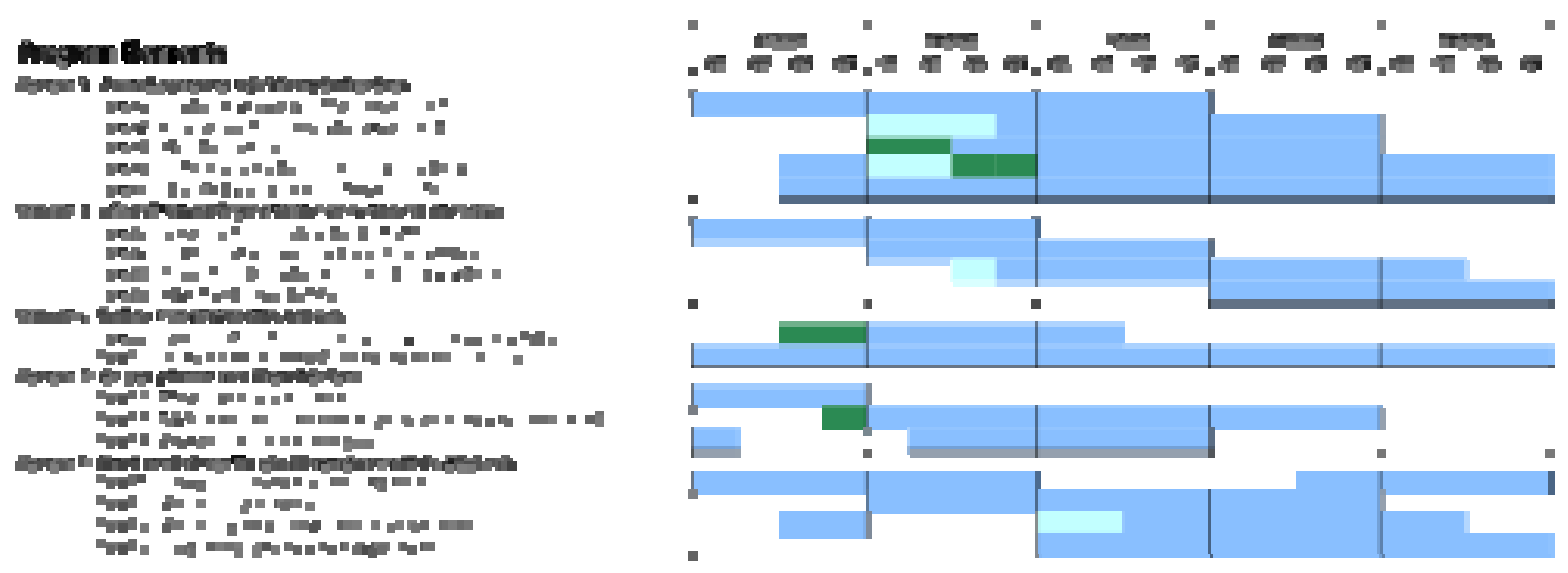

\section{4.a Review of Scientific Progress}

\section{4.a.i Brief Review of Scientific Progress}

\section{Program Element A: Binary Sorption to High-Affinity Surface Sites (M. Zavarin: lead; P. Zhao, S. Tumey, J. Begg)}

The focus of Program Element $\mathrm{A}$ is the study of $\mathrm{Pu}$ sorption in simple binary systems at $\mathrm{Pu}$ concentrations ranging from those observed in the field (attomolar to picomolar) to those commonly used in the lab (nanomolar to micromolar). The hypothesis guiding the effort in Program A is the following:

Colloid-facilitated Pu transport is fundamentally controlled by binary surface-complexation phenomena occurring on sites that have a range of sorption affinities, site-specific sorption/desorption kinetics, and redox transformation rates.

Testing this hypothesis requires the collection of sorption data over a range of (1) solution conditions, (2) $\mathrm{Pu}$ concentrations, and (3) colloid minerals. The kinetics of sorption and desorption will be quantified and an understanding of the underlying mechanisms controlling sorption affinities and sorption/desorption kinetics identified. Based on the collected data, a surface complexation model that includes kinetics and hysteresis effects (if necessary) will be developed.

\section{Task A1: $\quad$ Sorption Envelope and Isotherm Experiments}

In FY10, Pu-sorption experiments were successfully performed with the environmentally common mineral goethite $(\mathrm{FeOOH})$. These experiments were designed to not only quantify the sorption behavior of both $\mathrm{Pu}(\mathrm{IV})$ and $\mathrm{Pu}(\mathrm{V})$ over a ten order of magnitude concentration range but also to test the capabilities of the instruments at LLNL which are key to allowing us to probe Pu-mineral interactions at ultra-low concentrations. This comparison was completed in early FY11 (Fig. A1). We found that, below an equilibrium concentration of $10^{-9}$ $\mathrm{mol} / \mathrm{L}, \mathrm{Pu}$ sorption was linear and that $\mathrm{Pu}(\mathrm{IV})$ and $\mathrm{Pu}(\mathrm{V})$ reached equivalent sorption equilibria within 14 days. The linearity suggests that binary sorption to hypothetical high affinity sites at ultra-low Pu concentrations does not occur under these conditions ( $\mathrm{pH} 8 \mathrm{NaCl} / \mathrm{NaHCO}_{3}$ solutions). Whether this conclusion holds true over a wider range of solution conditions (e.g. ternary systems), reaction times, and mineral phases is the subject of ongoing research within this program.

At aqueous concentrations $>10^{-9} \mathrm{M}, \mathrm{Pu}(\mathrm{IV})$ "sorption" does not reach equilibrium within a 7-day experiment. The behavior can be attributed to a combination of surface-catalyzed reduction followed by surface precipitation and relatively slow homogeneous nucleation of $\mathrm{Pu}$ in solution. Homogeneous nucleation rates should increase with concentration due to an increasing thermodynamic driving force. On the other hand, surface catalyzed reduction and nucleation is limited by the access to surface sites at these concentrations. TEM characterization of these high concentration $\mathrm{Pu}$ sorption samples provide further insight into the surface precipitation of $\mathrm{Pu}$ on 
goethite (Fig. A2). Importantly, epitaxial growth of $\mathrm{Pu}_{4} \mathrm{O}_{7}$ on goethite in $\mathrm{Pu}(\mathrm{IV}$ ) sorption experiments (Powell et al., 2011) was reproduced in these experiments. Furthermore, $\mathrm{Pu}(\mathrm{V})$ sorption experiments resulted in the same epitaxial growth of $\mathrm{Pu}_{4} \mathrm{O}_{7}$. The relative abundance of $\mathrm{Pu}_{4} \mathrm{O}_{7}$ versus $\mathrm{PuO}_{2}$ varied as a function of $\mathrm{Pu}$ concentration and initial oxidation state. Thus, the relative abundance of these two forms of Pu nano-colloids is controlled by the rates of homogeneous $\mathrm{PuO}_{2}$ nucleation in solution, surface precipitation of $\mathrm{Pu}_{4} \mathrm{O}_{7}$, and surfacecatalyzed reduction of $\mathrm{Pu}(\mathrm{V})$ to $\mathrm{Pu}(\mathrm{IV})$.

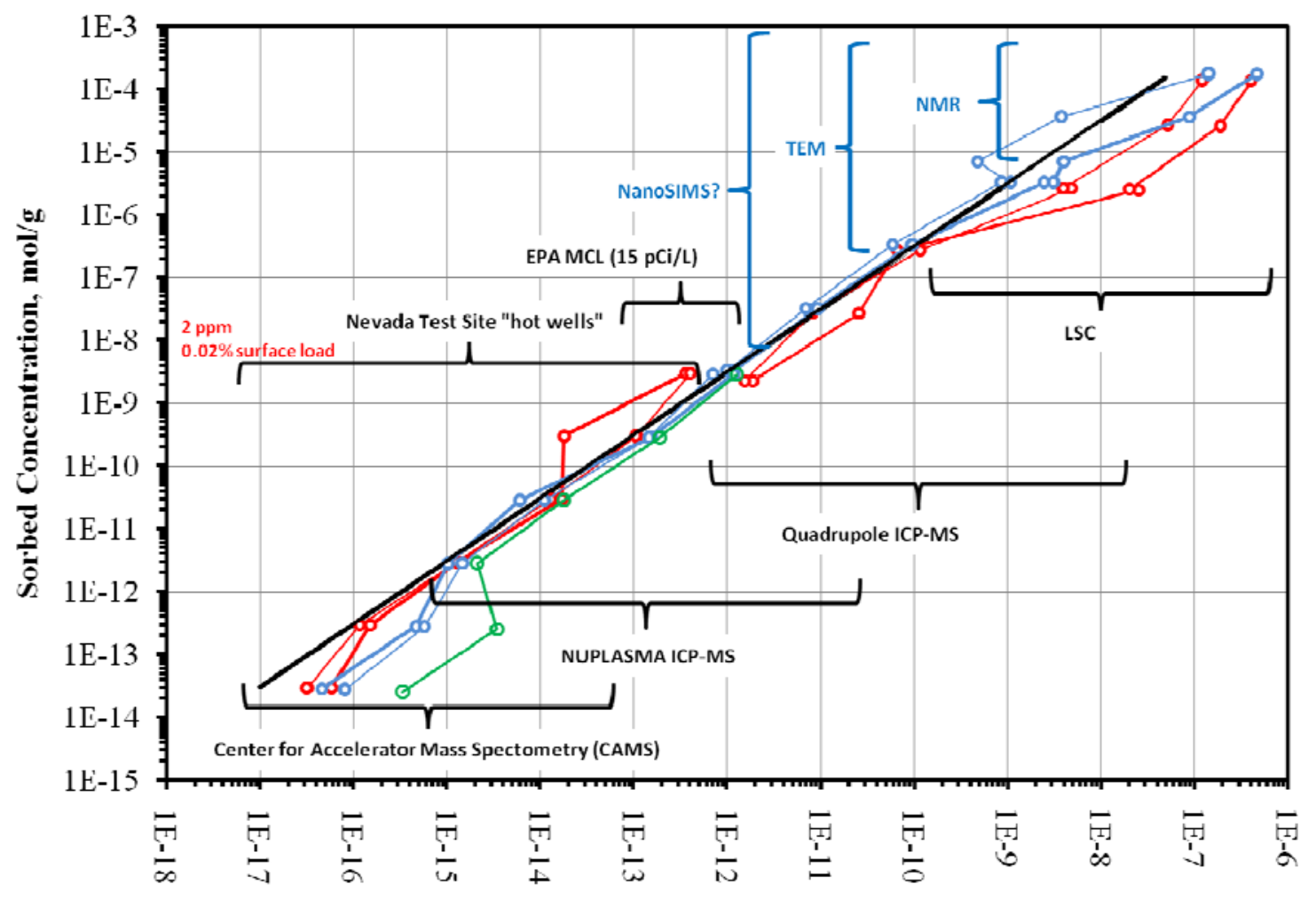

Aqueous Concentration, $\mathrm{mol} / \mathrm{L}$

Figure $\mathrm{A1}$. $\mathrm{Pu}(\mathrm{IV})$ (blue) and $\mathrm{Pu}(\mathrm{V})$ (red) sorption to goethite at 7 days (thick line) and 14 days (thin line). NuPlasma $\mathrm{Pu}(\mathrm{IV})$ data in green. All other low-level data collected by AMS.

With respect to comparing LLNL's capabilities for ultra-low Pu measurement, we found that AMS detection limits were one to two orders of magnitude lower than the NuPlasma ICP-MS for an equivalent volume of sample. However, detectable Pu was measured by AMS in sample blanks, leading to large errors in the lowest concentration samples (Fig. A1). As a result, we are establishing access to low-level laboratories for all FY11 and future ultra-low Pu sorption experiments.

In FY11 the focus has been to replicate the goethite experiments using montmorillonite (a smectite clay) to determine whether observations made for the behavior of $\mathrm{Pu}$ in the presence of goethite hold true for other environmentally relevant mineral phases. These experiments consist of $\mathrm{Pu}(\mathrm{IV})$ and $\mathrm{Pu}(\mathrm{V})$ batch sorption isotherms with montmorillonite at initial Pu concentrations ranging from $10^{-7}$ to $10^{-17} \mathrm{M}$. This approach again makes use of the many Pu counting techniques available at LLNL, including accelerator mass spectrometry (AMS), NuPlasma HR IsoProbe mass spectrometry and quadrupole ICP-MS. Experiments are on-going and results are expected within the next three months.

Preliminary work from this task has examined $\mathrm{Pu}(\mathrm{V})$ removal from solution in systems containing $0.1 \mathrm{~g} / \mathrm{L}$ and 1 $\mathrm{g} / \mathrm{L}$ montmorillonite and initial $\mathrm{Pu}$ concentrations of $5 \times 10^{-6} \mathrm{~mol} / \mathrm{L}$ and $5 \times 10^{-7} \mathrm{~mol} / \mathrm{L}$, which correspond to the highest adsorption isotherm concentrations. These experiments demonstrate that both the rate and extent of $\mathrm{Pu}(\mathrm{V})$ removal from solution was greater at $1 \mathrm{~g} / \mathrm{L}$ solid compared to $0.1 \mathrm{~g} / \mathrm{L}$ (Fig. A3). This is consistent with observations from FY10 goethite experiments where rate limited $\mathrm{Pu}(\mathrm{V})$ "sorption" at $\mathrm{Pu}$ concentrations above 
$10^{-9} \mathrm{M}$ was attributed to a lack of available surface sites for surface catalyzed $\mathrm{Pu}(\mathrm{V})$ reduction. Interestingly, there is a difference in the percentage removal of $\mathrm{Pu}(\mathrm{V})$ from solution between the two starting concentrations. The system with an initial $\mathrm{Pu}(\mathrm{V})$ concentration of $5 \times 10^{-6} \mathrm{~mol} / \mathrm{L}$ showed a greater relative removal of $\mathrm{Pu}$ from solution after 30 days compared to the system with an initial $\mathrm{Pu}(\mathrm{V})$ concentration of $5 \times 10^{-7} \mathrm{M}$. In previous experiments with goethite, it was suggested that at concentrations $>10^{-9} \mathrm{M}$, Pu removal from solution is driven by a combination of surface-catalyzed $\mathrm{Pu}(\mathrm{V})$ reduction and the homogeneous nucleation of $\mathrm{Pu}$ precipitates. As homogeneous nucleation rates are expected to increase with increasing Pu concentration due to an increasing thermodynamic driving force, the observed difference in Pu removal appears to highlight the importance of homogeneous nucleation in controlling $\mathrm{Pu}$ behavior in these systems.
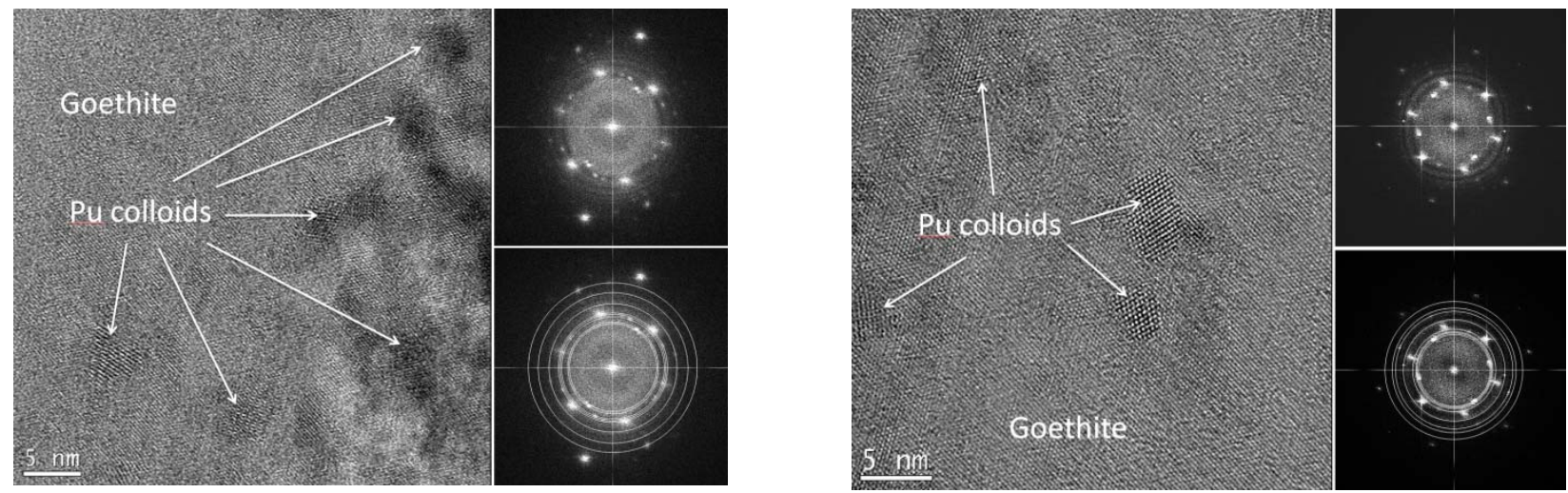

Figure. A2. Sorption of $\mathrm{Pu}(\mathrm{IV})(\mathrm{A})$ and $\mathrm{Pu}(\mathrm{V})(\mathrm{B})$ on goethite $(7000 \mathrm{ppm})$ results in equivalent epitaxial surface precipitation of $\mathrm{Pu}_{4} \mathrm{O}_{7}$.

A further outcome of this preliminary work was to help optimize the experimental parameters for the montmorillonite isotherm experiments, namely the solid:solution ratio to be used $(1 \mathrm{~g} / \mathrm{L})$ and the equilibration time (30 days). Isotherm experiments are underway and will be completed in FY11. FY10 efforts identified high $\mathrm{Pu}$ backgrounds during sample preparation. As a result we are developing clean lab facilities to analyze samples at femtomolar concentrations using the CAMS facility.
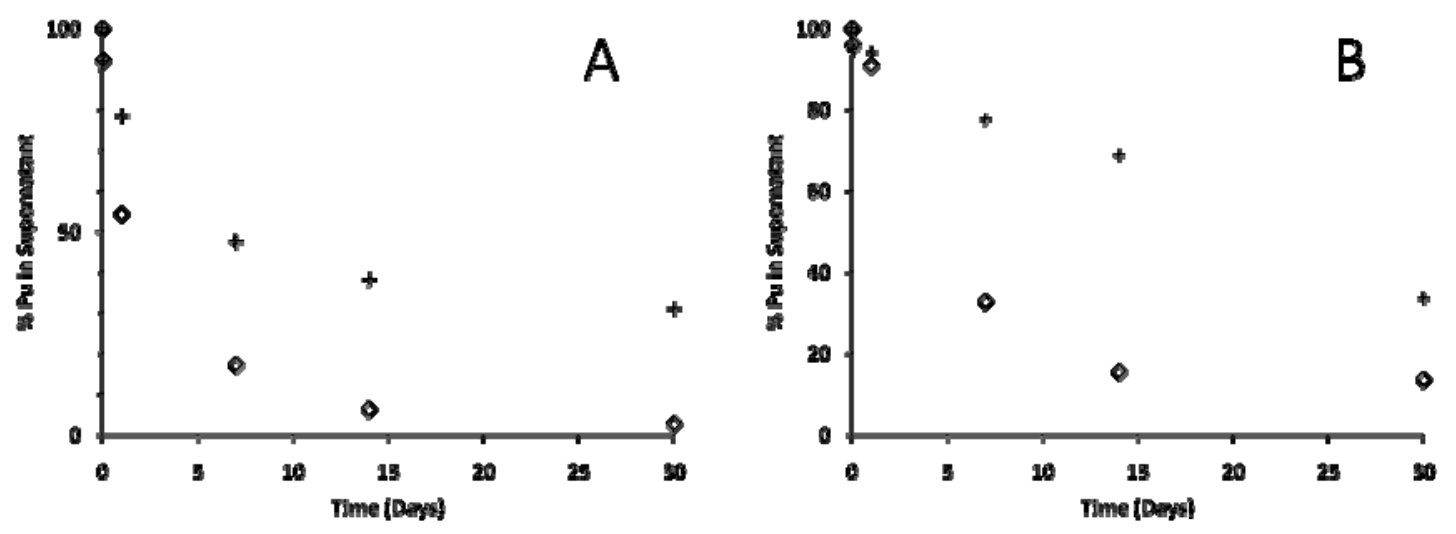

Figure A3. $\mathrm{Pu}(\mathrm{V})$ removal from solution in systems containing $0.7 \mathrm{mM} \mathrm{NaHCO} / 5 \mathrm{mM} \mathrm{NaCl}(\mathrm{pH} \sim 8)$ and: $1 \mathrm{~g} / \mathrm{L}$ montmorillonite $(\diamond) ; 0.1 \mathrm{~g} / \mathrm{L}$ montmorillonite $(+)$. Experiments were spiked to initial $\mathrm{Pu}(\mathrm{V})$ concentrations of $5 \times 10^{-6} \mathrm{M}$ (A) and $5 \times 10^{-7} \mathrm{M}(\mathrm{B})$.

Continuing FY11/FY12 work will investigate the stability of surface-associated Pu through a series of flow-cell sorption/desorption experiments at femtomolar Pu concentrations. This work will complement the existing batch adsorption data as well as providing us with a unique opportunity to study the coupled adsorptiondesorption processes impacting Pu behavior at environmentally relevant concentrations. These experiments will 
also include a study of the stability of intrinsic $\mathrm{Pu}(\mathrm{IV})$ nano-colloids in the presence of montmorillonite to compare stabilities of adsorbed $\mathrm{Pu}$, surface precipitated $\mathrm{Pu}$, and intrinsic $\mathrm{Pu}$ nano-colloids.

Fundamental to our understanding of surface-catalyzed $\mathrm{Pu}(\mathrm{V})$ reduction and sorption to mineral surfaces in binary systems is the identity of the reductant (electron donor). Naturally occurring chemical species such as humic/fulvic acids have been shown to alter the oxidation state and mobility of Pu (Banik et al., 2007). However, the $\mathrm{Pu}(\mathrm{V})$ reductant in binary sorption experiments has not been identified even though its reduction has been quantified in the presence of a number of oxidizing and redox-neutral minerals (Powell et al., 2004; 2005; 2006; Zavarin et al., 2005; submitted). A candidate molecule that may affect Pu redox kinetics in "binary" systems is hydrogen peroxide. Hydrogen peroxide may be produced as a result of radiolysis (Morgenstern and Choppin, 1999) and is also present at trace levels in natural waters via photo-oxidation of organic matter, deposition from the atmosphere, or other processes (Zika et al., 1985; Cooper et al., 1988). Previous work has demonstrated the ability of peroxide to reduce $\mathrm{Pu}(\mathrm{V})$ in solution (Morgenstern and Choppin, 1999). However, the role of mineral surfaces in potentially catalyzing this process has not been studied. Experiments performed in FY11 with ultrapure corundum $\left(\alpha \mathrm{Al}_{2} \mathrm{O}_{3}\right)$ with no known electron donor $(\mathrm{pH} 8)$ resulted in slow reduction of $\mathrm{Pu}(\mathrm{V})$ to $\mathrm{Pu}(\mathrm{IV})$. The addition of a large concentration of $\mathrm{H}_{2} \mathrm{O}_{2}$ enhanced the removal of $\mathrm{Pu}(\mathrm{V})$ from solution (Fig. A4). At high peroxide concentrations the presence of corundum does not increase reduction rates. However, factors such as $\mathrm{H}_{2} \mathrm{O}_{2}$ concentration, the solution $\mathrm{pH}$, and the type of mineral surface may alter the effect of hydrogen peroxide. Previous studies examining arsenic behavior have found that the presence of $\mathrm{H}_{2} \mathrm{O}_{2}$ combined with $\mathrm{Fe}^{3+}$ can enhance the oxidation of As(III) (Voeglin and Hug, 2003; Pettine and Millero, 2000). The combination of $\mathrm{H}_{2} \mathrm{O}_{2}$ and $\mathrm{Fe}^{3+}$ may have a similar effect on $\mathrm{Pu}(\mathrm{IV})$. Indeed, preliminary experiments performed with goethite at $\mathrm{pH} 4$ indicate that addition of hydrogen peroxide enhances desorption of $\mathrm{Pu}$ from the mineral surface, presumably by oxidizing surface associated $\mathrm{Pu}(\mathrm{IV})$ to $\mathrm{Pu}(\mathrm{V})$ (Fig. A5). Thus, it is clear that $\mathrm{H}_{2} \mathrm{O}_{2}$ may be considered an effective $\mathrm{Pu}(\mathrm{IV})$ oxidant or $\mathrm{Pu}(\mathrm{V})$ reductant depending on the specific aqueous and surface conditions present in a system.
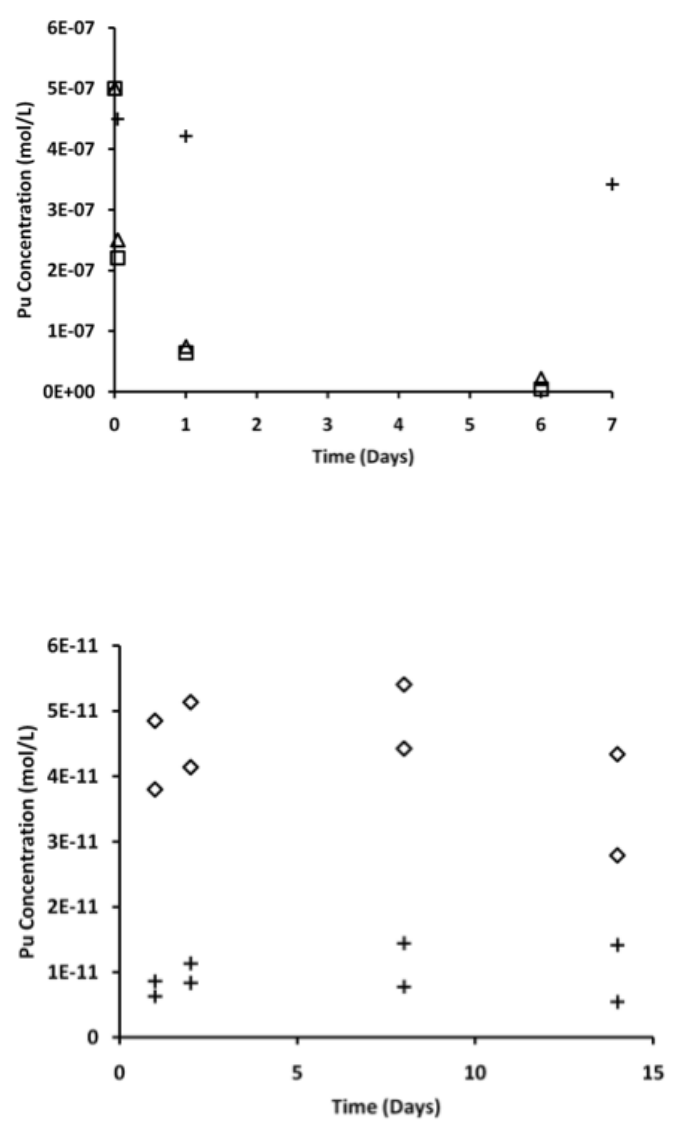

Figure A4. $\mathrm{Pu}(\mathrm{V})$ removal from solution in the presence of $\mathrm{H}_{2} \mathrm{O}_{2}$ and $\mathrm{Al}_{2} \mathrm{O}_{3}$. Plot shows $\mathrm{Pu}(\mathrm{V})$ in solution $(0.7 \mathrm{mM}$ $\mathrm{NaHCO}_{3} / 5 \mathrm{mM} \mathrm{NaCl}$ at $\mathrm{pH}=8$ ) versus time.

$(\Delta) 1 \mathrm{~g} / \mathrm{L} \alpha \mathrm{Al}_{2} \mathrm{O}_{3}$; plus $\mathrm{Pu}(\mathrm{V})$

(口) $1 \times 10^{-3} \mathrm{M} \mathrm{H}_{2} \mathrm{O}_{2}$; plus $\mathrm{Pu}(\mathrm{V})$

(+) $1 \mathrm{~g} / \mathrm{L} \alpha \mathrm{Al}_{2} \mathrm{O}_{3}$ plus $\mathrm{Pu}(\mathrm{V})$.
Figure A5. Desorption of $\mathrm{Pu}$ from goethite versus time. Initial sorption experiments contained $2 \mathrm{~g} / \mathrm{L}$ goethite in $0.01 \mathrm{M} \mathrm{NaCl}$ at $\mathrm{pH}=4$ and were spiked with $10^{-10} \mathrm{M} \mathrm{Pu}(\mathrm{IV})$. Solvent extraction on $\mathrm{T}=14 \mathrm{~d}$ samples indicated that $\mathrm{Pu}$ was present in solution as $\mathrm{Pu}(\mathrm{V})$.

(+) $0.01 \mathrm{M} \mathrm{NaCl}$ at $\mathrm{pH} 4$

(৩) $0.01 \mathrm{M} \mathrm{NaCl}$ at $\mathrm{pH} 4$ amended with 20 $\mathrm{mM} \mathrm{H}_{2} \mathrm{O}_{2}$. 


\section{Task A3: Ab-initio Modeling}

At extremely low concentrations, there are no spectroscopic techniques that allow interrogation of the electronic structure of elements on mineral surfaces. Thus, we have embarked on a program of computational work employing a range of $a b$ initio techniques including correlated wave function approaches (complete active space self-consistent field, CASSCF; multi-reference perturbation theory, MRPT) and density functional theory (DFT). We have also performed first-principles molecular dynamics within the DFT framework. Hardware resources available for this work include IBM BlueGene/L. Figure A6 is a schematic organization of various $a b$ initio methodologies in terms of computational cost versus accuracy. Note that model force fields, commonly used, are not $a b$ initio. Ab initio methodologies, although employ increasing cost (e.g. computational time), provide enhanced accuracy.

In general, the electronic structure of actinide (An) complexes poses numerous challenges for modeling. The high- $Z$ elements exhibit large relativistic and spin-orbit coupling effects. The description of open-shell $f$ electrons is problematic due to strong correlation effects. Accurate treatment of actinide complexes often require sophisticated correlated wave function techniques whose cost grows rapidly with the number of electrons, and thus are only practical for the small systems. To date, most theoretical work has focused on the actinyl complexes $\mathrm{AnO}_{2}{ }^{+}$and $\mathrm{AnO}_{2}{ }^{2+}$, for which detailed experiments in gas and aqueous phases are available for comparison and validation.

Methodologies with lower computational effort are possible (Fig. A6), but introduce uncontrolled approximations that require careful testing. The most common of these are based on DFT, which can potentially address larger and more complex systems. However, current approximations for exchange-correlation are not robust when applied to actinides. For example, DFT within the generalized gradient approximation (GGA) for solid $\mathrm{PuO}_{2}$ oxide incorrectly yields a ground state that is metallic, when in fact it should be insulating. Hybrid functionals improve on this, giving the correct insulating ground state of solid $\mathrm{PuO}_{2}$. On the other hand, for the $\mathrm{PuO}_{2}{ }^{2+}$ and $\mathrm{PuN}_{2}$ molecules, DFT-GGA predicts ground state structures and vibrational frequencies that are in good agreement with multi-reference perturbation theory, while hybrid functionals exhibit worse agreement compared to DFT-GGA. Thus, before continuing on any extensive $a b$ initio simulations, we first carried out benchmark studies.

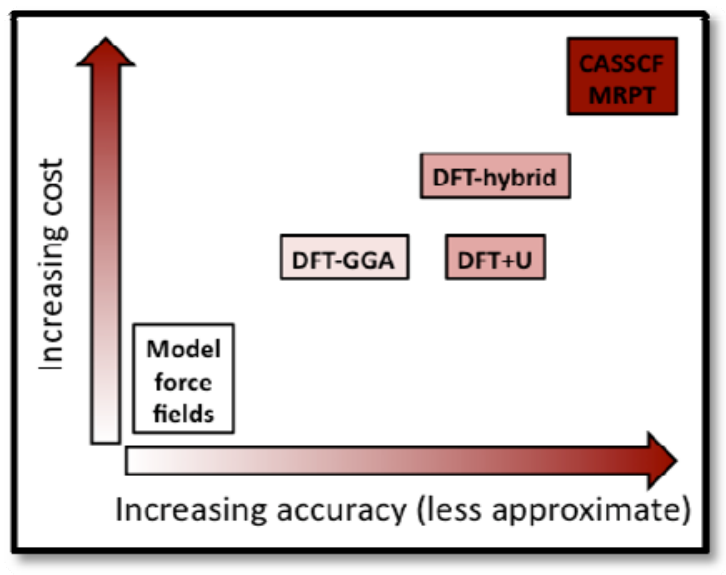

Figure A6: Schematic organization of various $a b$ initio methodologies in terms of computational cost versus accuracy. Note that model force fields are not $a b$ initio. Molecular dynamics with model force fields is commonly utilized for the simulation of aqueous geochemical systems; it is included here for comparison with the $a b$ initio approaches that we employ in our work.

Our $a b$ initio modeling efforts are currently focused on the atomic-scale behavior of monomeric $\mathrm{Pu}(\mathrm{OH})_{4}$ in aqueous environments, which is expected to be the predominant species at $\mathrm{Pu}(\mathrm{IV})$ concentrations of $<10^{-10} \mathrm{M}$ near neutral pH (Neck and Kim, 2001). Currently available spectroscopic techniques are not capable of detailed characterization at such low concentrations, and thus we turn to $a b$ initio modeling to gain insights into the structure and chemical reactivity of monomeric $\mathrm{Pu}(\mathrm{IV})$ at environmental conditions. However, the electronic structure of actinides poses numerous challenges for theory, and thus in FY10 we began with benchmark studies to evaluate the performance of various $a b$ initio methodologies. We concluded that standard density functional 
theory (DFT) within the generalized gradient approximation (GGA) provided a poor description of the electronic structure of $\mathrm{Pu}(\mathrm{OH})_{4}$. This is problematic, because $a b$ initio simulations of condensed phases are most straightforwardly and efficiently carried out using the DFT-GGA.
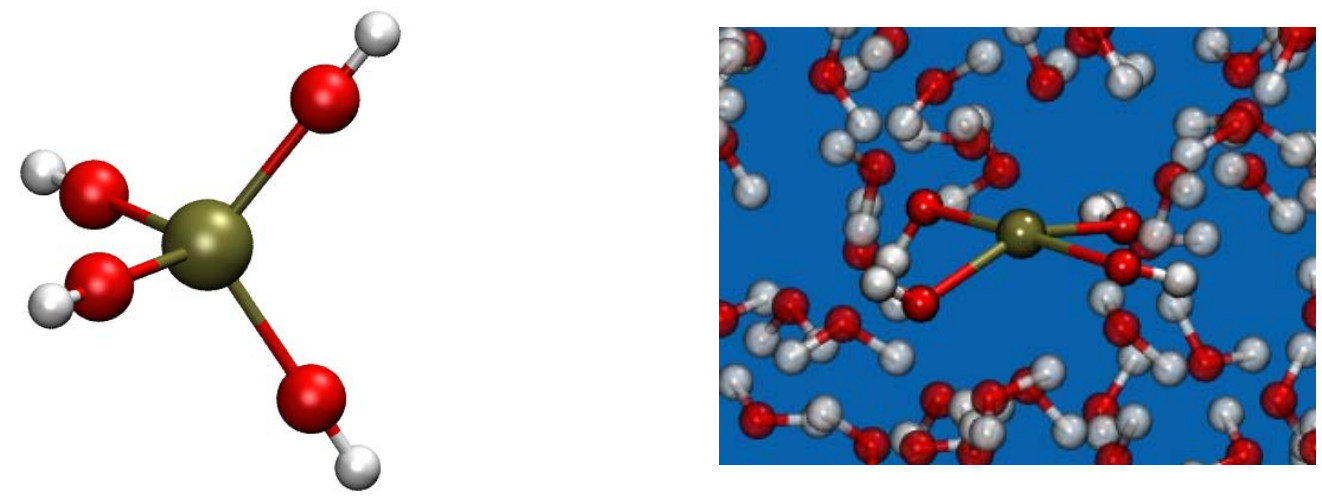

Figure A7, Left: Optimized $\mathrm{Pu}(\mathrm{OH})_{4}$ structure in the gas phase (i.e., no coordinated waters) is tetrahedral. The central gold atom indicates $\mathrm{Pu}$, while red and white atoms denote $\mathrm{O}$ and $\mathrm{H}$, respectively. Right: Snapshot from ab initio molecular dynamics simulation of $\mathrm{Pu}(\mathrm{OH})_{4}$ in a periodic simulation cell of 96 water molecules at ambient temperature and pressure. The presence of a bulk water environment stabilizes a distorted planar geometry for $\mathrm{Pu}(\mathrm{OH})_{4}$.

In FY11, we developed an approach for the ab initio simulation of $\mathrm{Pu}(\mathrm{OH})_{4}$ in aqueous environments based on DFT $+\mathrm{U}$ method. In short, this is an extension of standard DFT-GGA where an additional Hubbard-like term is included to describe the $5 \mathrm{f}$ electron correlations in $\mathrm{Pu}$, while still retaining the computational efficiency of DFTGGA. While the application of DFT+U to solid-state systems has a long history, here we propose to apply the $\mathrm{DFT}+\mathrm{U}$ method to chemical problems in the liquid state. Our strategy follows from prior work on transition metal oxides (Mosey et al, 2008), where the parameters that enter into the DFT $+\mathrm{U}$ are calculated from first principles. A set of DFT $+\mathrm{U}$ parameters appropriate for aqueous $\mathrm{Pu}(\mathrm{OH})_{4}$ is determined by systematically evaluating a series of hydrated $\mathrm{Pu}(\mathrm{OH})_{4}\left(\mathrm{H}_{2} \mathrm{O}\right)_{n}$ clusters of increasing size (up to $n=5$ ), which accounts for the dominant influence due to the first solvation shell of water.

We have successfully applied this DFT $+\mathrm{U}$ model to $a b$ initio molecular dynamics (MD) simulations of $\mathrm{Pu}(\mathrm{OH})_{4}$ in a bulk water environment at ambient temperature (Huang et al, submitted 2011). In FY10, we found that the lowest energy structure for gas phase $\mathrm{Pu}(\mathrm{OH})_{4}$ is tetrahedral (Fig. A7, left), which is the geometry that minimizes the repulsion between the negatively charged $\mathrm{OH}^{-}$ligands. On the other hand, our ab initio MD simulations for aqueous $\mathrm{Pu}(\mathrm{OH})_{4}$ indicate that the presence of a bulk liquid environment stabilizes a distorted planar structure (Fig. A7, right). This example illustrates the importance of explicitly including water in atomicscale modeling of monomeric $\mathrm{Pu}(\mathrm{IV})$. Our current work now involves extending these simulations to examine the adsorption of monomeric $\mathrm{Pu}(\mathrm{IV})$ at a model mineral/water interface, starting with the diaspore/water interface as a structural analogue for the goethite/water interface.

\section{Program Element B: Stabilization of Pu Surface Complexes on Mineral Colloids by Natural Organic Matter \\ (B. Powell: lead; R. Tinnacher, Students: L. Simpkins, J. Wong, T. Zimmerman)}

The focus of Program Element B is to examine the influence of natural organic matter (NOM) on Pu sorption to pure mineral phases and sediments. The task is guided by the following hypothesis: 
NOM can increase Pu mobility by 1) forming NOM coatings on colloids that stabilize Pu surface complexes and 2) formation of aqueous $\mathrm{Pu}$-NOM complexes which decrease sorption of Pu and increase subsurface mobility.

The research plan consists of four tasks; the first two focus on equilibria of Pu-NOM (binary systems) and PuNOM-mineral (ternary systems) interactions. There is a strong coupling of these tasks with the binary $(\mathrm{Pu}-$ mineral) studies described in Program Element A.

Our FY11 milestone was to continue examination of the influence of NOM fractions on Pu sorption to pure mineral phases and to begin quantifying the data through aqueous and surface complexation modeling. We have met this milestone. Sorption experiments using gibbsite $\left(\alpha-\mathrm{Al}(\mathrm{OH})_{3}\right)$ and goethite $(\alpha-\mathrm{FeOOH})$ have been performed using NOM surrogates such as Leonardite humic acid (HA), Suwannee River fulvic acid (FA), desferroxamine-B (DFOB), and citric acid (Task B1). We have begun interpreting the data in terms of an aqueous and surface complexation model. In FY11, we also determined stability constants for Pu-FA complexation (Task B2). The results from Task B1 have indicated that NOM can either enhance or decrease $\mathrm{Pu}$ sorption depending on specific NOM characteristics and chemical solution conditions, such as $\mathrm{pH}$. To demonstrate the relevance of these effects on Pu subsurface mobility, we have begun some of the column experiments in Task B4. This is slightly ahead of schedule but deemed necessary to demonstrate the implications of some of the knowledge gained in Tasks B1 and B2.

\section{Task B1: $\quad$ Screening for Enhanced Pu Mobilization by NOM}

The objective of this task is to examine representative NOM surrogates (citric acid, desferroxamine-B, extracellular polymeric substances, FA, and HA) to determine their influence on Pu sorption to minerals and sediments. To date, our experiments have focused on Pu sorption to gibbsite $\left(\alpha-\mathrm{Al}(\mathrm{OH})_{3}\right)$ and goethite $(\alpha-$ $\mathrm{FeOOH}$ ). The overall observation is that NOM can cause either enhanced or reduced sorption to pure minerals depending on $\mathrm{pH}$ of the system, the character of the NOM, and the type of mineral involved. Particularly at low $\mathrm{pH}$ values, our data indicate that ternary surface complexes are forming and preliminary surface complexation constants have been determined. It also appears that smaller, more hydrophilic ligands such as citric acid and DFOB can stabilize aqueous Pu complexes more readily than larger ligands with both hydrophilic and hydrophobic components such as HA.

\section{Influence of NOM on Pu sorption to gibbsite}

The sorption of Pu to gibbsite in the presence of four types of NOM is shown in Figure B1. Previous experiments have shown nearly complete sorption of $\mathrm{Pu}(\mathrm{IV})$ to the mineral phase in ligand-free systems above pH 4 (Zimmerman, 2010; Powell et al., 2008). The data presented in Figure B1 shows that the presence of FA, $\mathrm{DFOB}$, and citric acid causes an increase in aqueous $\mathrm{Pu}$ concentrations and a decrease in the Pu fraction sorbed relative to FA free systems. The most significant difference can be observed in the citric acid and DFOB systems. At low $\mathrm{pH}$ values, a slight increase in sorption relative to the ligand free system was seen in the presence of HA. This is consistent with the observations reported in the work done in FY10 (Zimmerman, 2010). Across the $\mathrm{pH}$ range 5-9, Pu sorption increases with increasing $\mathrm{pH}$ for systems containing FA, DFOB, and citric acid. In this region, the mineral surface charge transitions from a net positive to a net negative charge resulting in competition between the ligand and the surface for complexation/sorption of $\mathrm{Pu}(\mathrm{IV})$. Conversely, sorption of the ligand is expected to decrease with increasing $\mathrm{pH}$ (ligand-like sorption behavior). This was verified for FA (data not shown) and is consistent with anionic functional groups of FA interacting with positively charged gibbsite sites at low $\mathrm{pH}$ and being repelled by negatively charged sites at higher $\mathrm{pH}$. 
Fulvic Acid

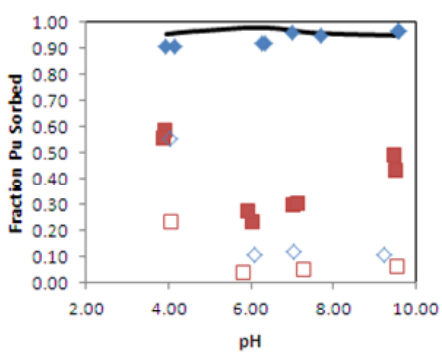

Citric Acid

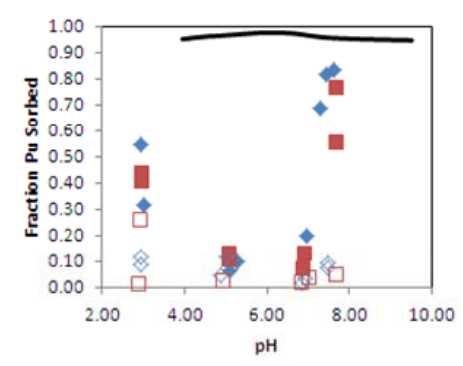

Humic Acid

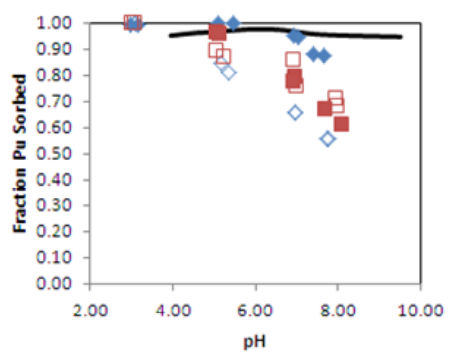

DFOB

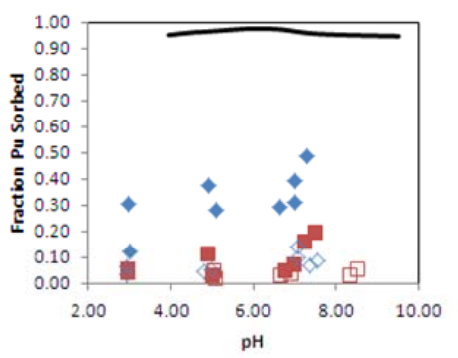

Figure B1: The effect of different ligands on the sorption of $\mathrm{Pu}(\mathrm{IV})$ to gibbsite. Data collected after a 7 day equilibration period. Solid phase separated from aqueous phase by $30 \mathrm{k}$ MWCO filtration.

System parameters: Gibbsite concentration of $5 \mathrm{~g} / \mathrm{L}$; Pu-238 concentration of $10^{-10} \mathrm{M}$; $0.1 \mathrm{M} \mathrm{NaCl}$ background; $5 \mathrm{mg}_{\mathrm{C}} / \mathrm{L}$ (diamonds) and $50 \mathrm{mg}_{\mathrm{C}} / \mathrm{L}$ (squares); closed symbols represent systems containing gibbsite and open symbols represent systems without gibbsite present. *Note: FA samples were prepared as mg FA/L.

Therefore, the carbon concentrations are $2.62 \mathrm{mg}_{\mathrm{C}} / \mathrm{L}$ and $26.22 \mathrm{mg}_{\mathrm{C}} / \mathrm{L}$. The solid line in each figure represents a surface complexation model for Pu-gibbsite developed from sorption data in the absence of NOM (Powell et al., 2008 and Zimmerman, 2010).

\section{Influence of NOM on Pu sorption to goethite}

In order to examine the influence of mineral characteristics on $\mathrm{Pu}$ sorption behavior, we also performed $\mathrm{Pu}$ sorption experiments to goethite. First experiments were set at $\mathrm{pH} 4$ to evaluate the possibility of ternary surface complex formation, and to promote the potential formation of NOM coatings on the mineral surface. Enhanced sorption of $\mathrm{Pu}$ to goethite in the presence of FA was observed (Fig. B2), which is consistent with the formation of ternary surface complexes. The overall observation of ternary surface complex formation is consistent with $\mathrm{Pu}$ sorption behavior in gibbsite systems, as discussed above. However, the degree of enhanced Pu sorption at low $\mathrm{pH}$ is much greater, which reflects stronger binding of Pu-FA complexes to goethite than to gibbsite. This will be further examined in future years with hematite and corundum phases.

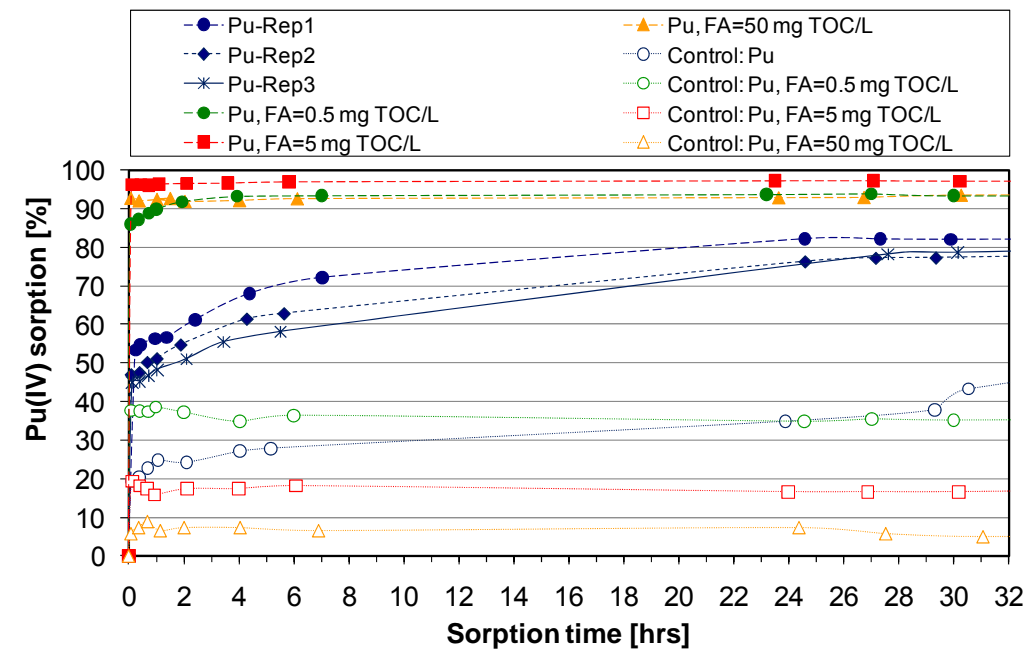

Figure B2: Sorption of $10^{-10} \mathrm{M} \mathrm{Pu}(\mathrm{IV})$ (initial oxidation state) to $2 \mathrm{~g} / \mathrm{L}$ goethite in $0.01 \mathrm{M}$ $\mathrm{NaCl}$ at $\mathrm{pH}=4$ as a function of time and in the presence and absence of FA. Controls represent systems with the same chemical solution conditions but in the absence of goethite. The data indicate that both the rate and extent of $\mathrm{Pu}$ sorption are increased in the presence of FA. 


\section{Thermodynamic Modeling of Batch Sorption Systems}

In order to examine the possible impact of ternary surface complexes and aqueous speciation, we developed thermodynamic models for the Pu-gibbsite systems discussed above. The first effort was to predict sorption of $\mathrm{Pu}(\mathrm{IV})$ in the presence of a ligand by assuming only the formation of $\mathrm{Pu}-\mathrm{AlOH}$ surface complexes and $\mathrm{Pu}-$ ligand solution complexes. This modeling approach provided acceptable fits to the data at neutral and high $\mathrm{pH}$ values. This is expected based on the proposed sorption mechanisms occurring in each system. It is noteworthy

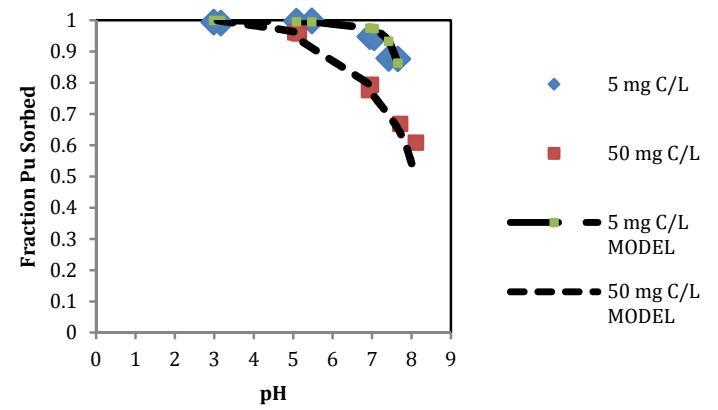

Figure B3: Data and model prediction of Pu sorption to gibbsite in the presence of HA. Data were modeled assuming the formation of ternary surface complexes. that in most models, at high $\mathrm{pH}$ systems there is typically a point where $\mathrm{Pu}(\mathrm{IV})$ hydrolysis begins to occur, which outcompetes organic ligand complexation. This is manifested by increased sorption at high $\mathrm{pH}$ such as that observed in the Pu-gibbsite-citric acid system. The increase could also be due to formation of intrinsic $\mathrm{PuO}_{2}$ colloids, although the systems are not necessarily saturated.

In all cases, a satisfactory fit to the low $\mathrm{pH}$ data was not achieved when using only binary surface reactions. Therefore, the data were remodeled and the formation of ternary surface complexes was included. An example of the model fits obtained is shown in Figure B3. This model is based on aqueous complexation by HA as previously quantified in this task (Zimmerman, 2010). The final surface complexation constant and reaction are:

$\equiv \mathrm{AlOH}+\mathrm{Pu}^{4+}+2 \mathrm{H}_{2} \mathrm{O}+2 \mathrm{HL} 3 \rightarrow \mathrm{AlOH}_{2} \mathrm{Pu}(\mathrm{OH})_{2}(\mathrm{HL} 3)_{2}{ }^{3+}+\mathrm{H}^{+} \quad \log \mathrm{K}=36.0$.

\section{Task B2: Determination of Stability Constants for Relevant Pu-NOM Complex}

Task B2 is focused on verifying and enhancing existing thermodynamic data for Pu-NOM complexation. Data for actinide binding to NOM are sparse. However, in order to quantify the fate and transport of Pu in subsurface environments, reliable aqueous complexation data are required. Similar to the Pu-HA constants determined in FY10 efforts (Zimmerman 2010), we determined Pu-FA stability constants using a discrete ligand binding approach. However, due to the overall low molecular weight distribution of FA as compared with HA, an ultrafiltration separation scheme was not possible; hence, a solubility-based approach was taken. Fulvic acid was added to saturated $\mathrm{Pu}(\mathrm{IV})$ systems in which $\mathrm{PuO}_{2}$ (s) was formed and the increase in aqueous $\mathrm{Pu}$ concentrations due to complexation with FA was monitored over time. To date, the samples have been equilibrating for 16 weeks, and as of 13 weeks, have not reached apparent equilibrium. The samples will continue to be monitored and after a steady state is reached, the stability constants will be determined. However, important kinetic dissolution data have been obtained from these experiments. The dissolution rate of $\mathrm{PuO}_{2}(\mathrm{~s})$ in the presence of FA are shown in Figure B4. There is relatively little influence of $\mathrm{pH}$ within a range from $\mathrm{pH} 4$ to 7.5 on the rate but the rate does increase with increasing FA concentration. This weak $\mathrm{pH}$ dependency is possibly explained by a relatively strong binding of $\mathrm{Pu}$ with $\mathrm{FA}$ across the entire $\mathrm{pH}$ region examined. This has also been observed for $\mathrm{Pu}-\mathrm{HA}$ binding across the same $\mathrm{pH}$ range. The data show an initial rapid dissolution rate followed by a steady state dissolution rate of approximately $0.5 \mu \mathrm{g}_{\mathrm{Pu}} / \mathrm{L} /$ day. 


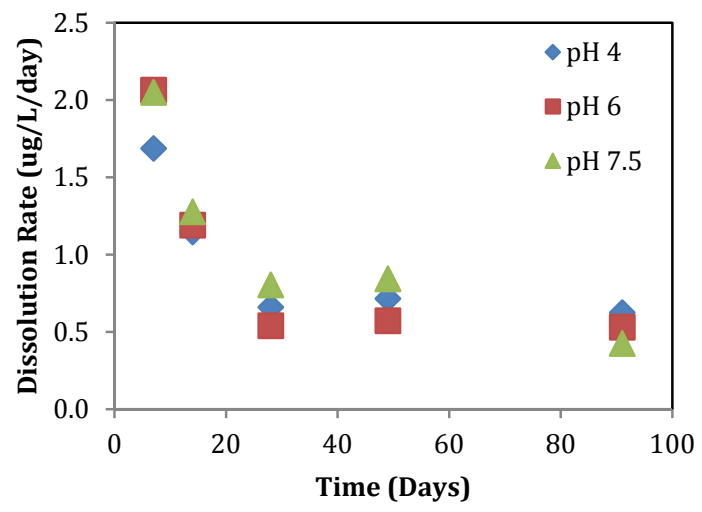

Figure B4: Dissolution rate of $\mathrm{PuO}_{2}(\mathrm{~s})$ over time in $50 \mathrm{mg}_{\mathrm{C}} / \mathrm{L} \mathrm{FA}$ in a $0.1 \mathrm{M} \mathrm{NaCl}$ background. Solid phase separated from aqueous phase by 30k MWCO filtration. Dissolution rate was calculated by dividing the total $\mathrm{Pu}-242$ concentration by the number of days of equilibration. A similar dataset with $5 \mathrm{mgC} / \mathrm{L} \mathrm{FA}$ is also available and shows a similar trend but a slightly slower rate indicating the influence of the FA concentration.

\section{Task B4: Advective Transport of Pu in the Presence of Mineral Colloids and NOM}

To demonstrate the potential for enhanced subsurface mobility due to the formation of soluble Pu-ligand complexes, a series of 1-D column experiments were performed. A subsurface sandy loam sediment from the Savannah River Site F-Area was packed into $8.3 \mathrm{~cm}$ x $1.5 \mathrm{~cm}$ columns and Pu-ligand complexes were injected as a one column volume finite step. Consistent with the enhanced sorption of $\mathrm{Pu}$-ligand complexes at low $\mathrm{pH}$ values, the mobility of $\mathrm{Pu}$ in the presence of $\mathrm{HA}$ at $\mathrm{pH} 4$ and $\mathrm{FA}$ at $\mathrm{pH} 5$ was significantly decreased relative to a soluble $\mathrm{Pu}(\mathrm{V})$ system (data not shown). Data for $\mathrm{Pu}(\mathrm{V})$ were obtained from Powell et al., (2002). However, in a pH 7 system containing DFOB, Pu mobility was quite similar to that of soluble $\mathrm{Pu}(\mathrm{V})$ (Figure B5). Thus, consistent with batch sorption experiments, the mobility of $\mathrm{Pu}$ in the presence of NOM does appear to be profoundly influenced by the $\mathrm{pH}$ of the system. This is due to changes in $\mathrm{Pu}$ and NOM sorption affinities and in the relevance of $\mathrm{Pu}-\mathrm{NOM}$ complexation reactions as a function of $\mathrm{pH}$.

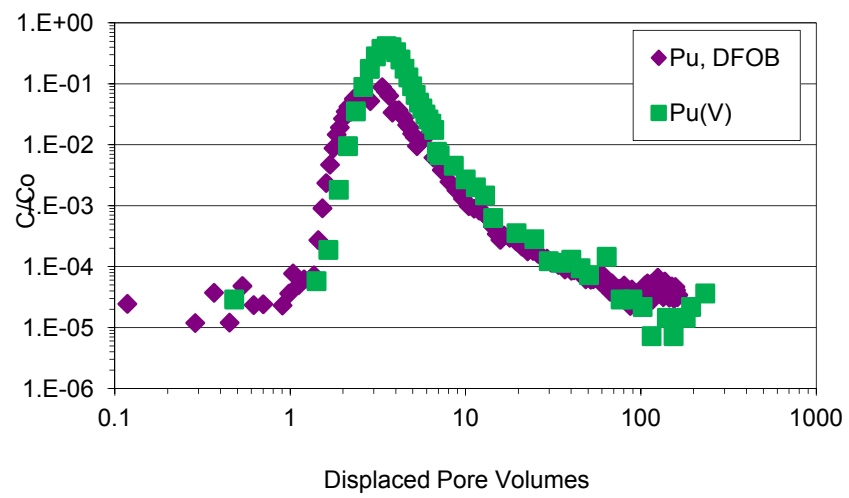




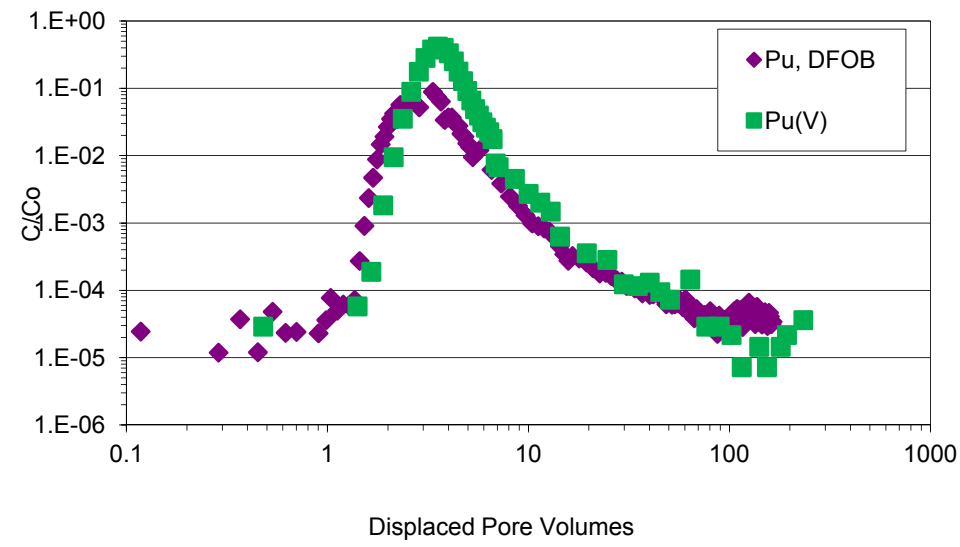

Program Element C: $\quad$ Surface Precipitation of Pu Colloids: Experimental and
Figure B5: Normalized Pu concentration in column effluent indicating similar profiles of soluble $\mathrm{Pu}(\mathrm{V})$ and $\mathrm{Pu}(\mathrm{IV})$-DFOB complexes. Note that in both cases $\mathrm{Pu}$ was added as a one column volume finite step. $\mathrm{Pu}(\mathrm{V})$ data from Powell et al., (2002). Natural Nanocolloids

\section{(A. Kersting: lead; B. Powell, Z. Dai, R. Kips, and P. Zhao)}

The focus of Program Element $\mathrm{C}$ is to characterize the conditions under which $\mathrm{Pu}$ sorbs as a precipitate versus when it sorbs as monomeric surface complex. A second objective is to understand how our experimental findings compare with natural colloids contaminated with $\mathrm{Pu}$ at several field sites. This Program Element is strongly integrated with Program Elements A, B D and E. We are testing the following hypothesis:

The apparent sorption/desorption of Pu to mineral colloids is the result of surface precipitation of pure Pu nanopolymers. The stability/solubility of the Pu colloids will be affected by their depositional characteristics and interaction with the mineral surface.

The low solubility of $\mathrm{Pu}(\mathrm{IV})$ must be considered in any interpretation of laboratory sorption experiments conducted at relatively high concentrations $\left(>10^{-9} \mathrm{M}\right)$ that could likely result in precipitation of $\mathrm{PuO}_{2}$ polymer as a result of oversaturated solution conditions. Recent work by Neck et al. (2007)and Soderholm et al. (2008) sheds light on previously conflicting $\mathrm{Pu}(\mathrm{IV})$ solubility studies, suggesting that aqueous $\mathrm{Pu}(\mathrm{V})$ and 2- to 20-nm $\mathrm{Pu}$ colloids are expected to be present in solution. Thus, most laboratory $\mathrm{Pu}$ "sorption" experiments carried out at $\mathrm{Pu}$ concentrations greater than $10^{-9} \mathrm{M} \mathrm{Pu}(\mathrm{IV})$ should, in fact, be regarded as reflecting adsorption of $\mathrm{Pu}$ in multiple oxidation states and the interaction of colloidal $\mathrm{Pu}(\mathrm{IV})$ clusters with mineral surfaces.

In FY10 our experimental milestones were to finish our preliminary investigation of the structure of $\mathrm{Pu}(\mathrm{IV})$ colloids on goethite and silica and expand this effort to include $\mathrm{Pu}(\mathrm{V})$ (Task $\mathrm{C} 1$ ). Of particular interest is understanding what surface loading and aqueous concentrations results in incipient $\mathrm{Pu}$ polymerization at high $\mathrm{Pu}$ concentrations. An additional milestone was to initiate external collaborations to investigate natural colloids samples from a contaminated DOE site (Task C2). We completed all our milestones and started one additional collaboration involving examination of samples from Russia. The results of the first part of Task $\mathrm{C} 1$ were written up in manuscirpt form and recently published (Powell et al., 2011). For Task C2, samples from Hanford Reservation were analyzed by SEM and NanoSIMS as part of a new collabration with Andy Felmy at (PNNL). In addition, aquifer solids from Tomsk, Russia, a radionuclide waste injection site, were analysed as a result of a new collaboration with Stepan Kalmykov at Moscow State University.

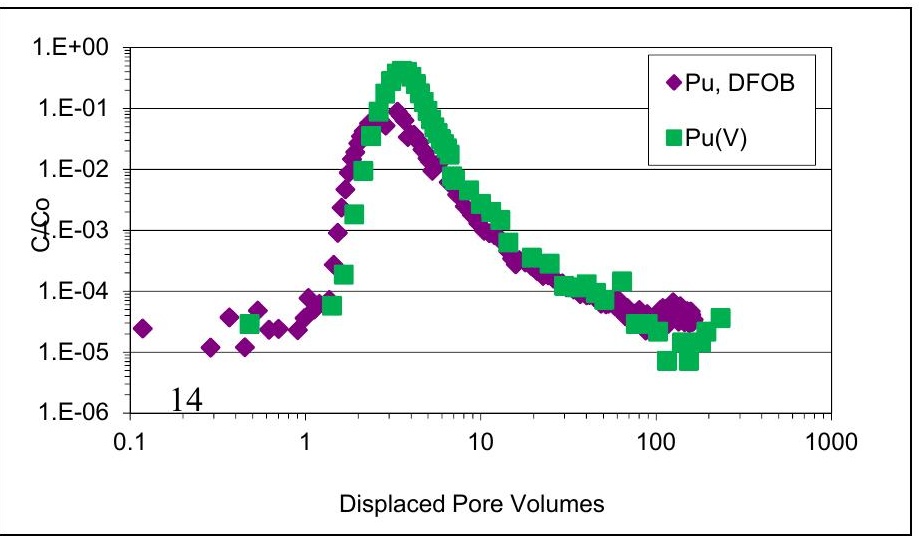




\section{Task C1: $\quad$ Experimental Determination of Monomeric Versus Polymeric Pu Precipitation}

In FY10 we completed a series of experiments focused on characterizing the chemical form of Pu on mineral surfaces. This work was submitted as a publication and published in FY11 (Powell et al., 2011). Particular emphasis was placed on identifying Pu concentrations and solution conditions that result in the formation of $\mathrm{Pu}$ colloids. In one study, the nanostructure of Pu colloids was investigated using high-resolution TEM for four different samples; 1) intrinsic Pu nano-colloids, 2) intrinsic Pu nano-colloids added to goethite colloids, 3) dissolved $\mathrm{Pu}(\mathrm{IV})$ added incrementally to goethite, and 4) dissolved $\mathrm{Pu}(\mathrm{IV})$ added incrementally to quartz.

Intrinsic $\mathrm{Pu}$ nano-colloids that were formed were 2-5 nm in diameter, and both electron diffraction analysis and HRTEM confirm the expected Fm3m space group with the fcc, $\mathrm{PuO}_{2}$ structure. In the experiment in which intrinsic Pu nano-colloids were formed first and then mixed with goethite colloids, the majority of the Pu nanocolloids did not associate with goethite, but instead remained as colloid nanoclusters captured on the carbon film of the TEM grid. High-resolution TEM imaging (Fig. C1) and FFT analysis of the intrinsic Pu nano-colloids retained the same $f c c \mathrm{PuO}_{2}$ structure as the original intrinsic $\mathrm{Pu}$ nano-colloids. In contrast, Pu nano-colloids formed by incrementally adding a dissolved $\mathrm{Pu}(\mathrm{IV})$ solution to a goethite suspension formed $2-5 \mathrm{~nm}$ nanoclusters on the mineral surface (Fig. C2). High-resolution imaging and electron diffraction analysis show that these nanoclusters do not have the expected Fm3m space group, but rather the Ia3 space group, matching the bcc $\mathrm{Pu}_{4} \mathrm{O}_{7}$ structure.

The plutonium nano-colloids that formed on goethite have undergone a lattice distortion relative to the ideal fluorite-type structure, fcc, $\mathrm{PuO}_{2}$, resulting in the formation of a bcc, $\mathrm{Pu}_{4} \mathrm{O}_{7}$ structure. This structural distortion results from an epitaxial growth of the plutonium colloid on goethite, resulting in a stronger binding of plutonium to goethite compared with other minerals such as quartz for which this distortion was not observed. This finding provides new insight for understanding how molecular-scale behavior at the mineral-water interface may facilitate transport of plutonium at the field scale.
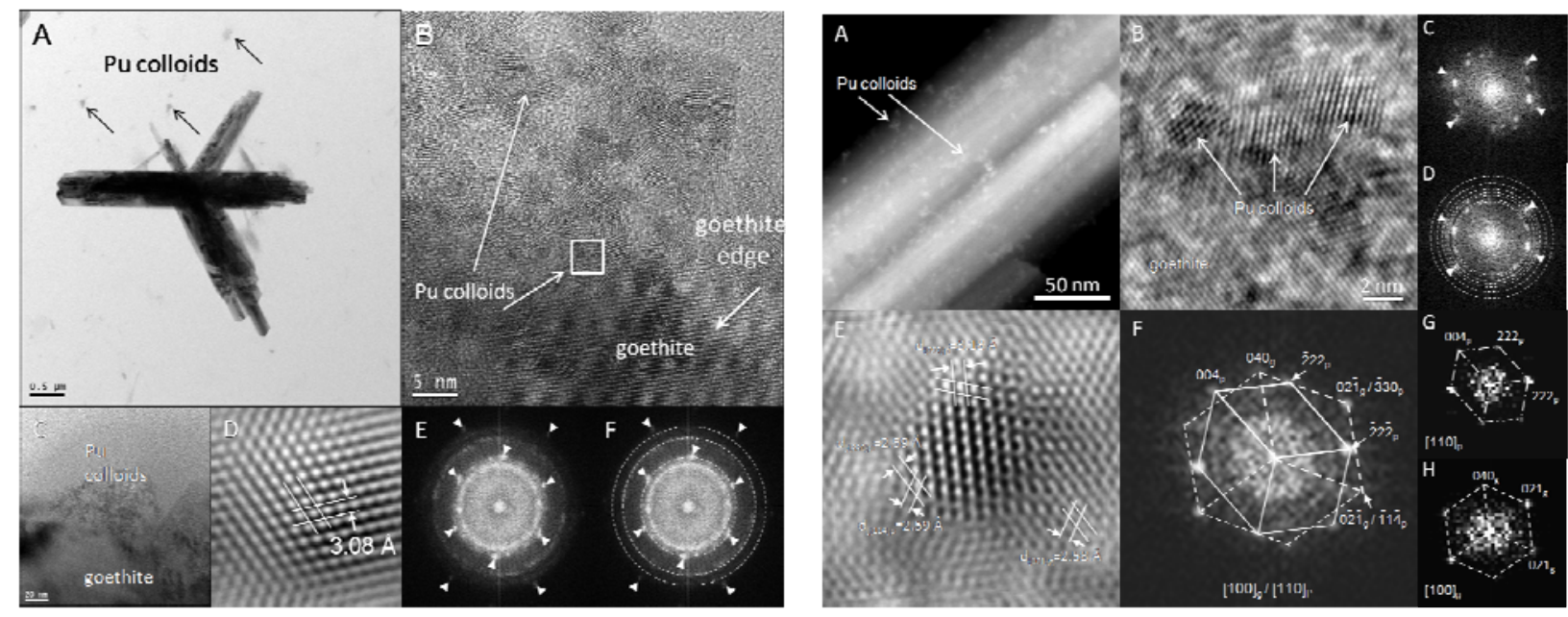

Figures C1 and C2. The composite figure, $\mathrm{C} 1$ (left) shows Pu colloids located off the goethite crystal with the expected the fcc, $\mathrm{PuO}_{2}$ structure. $\mathrm{C} 2$ (right) shows $\mathrm{Pu}_{4} \mathrm{O}_{7}$ nano-colloids formed in situ on goethite.

The work continues in FY11. We are currently looking at $\mathrm{Pu}(\mathrm{IV})$ and $\mathrm{Pu}(\mathrm{V})$ colloids growing in the presence of Groutite $(\mathrm{MnOOH})$ and Diaspore $(\mathrm{AlOOH})$ in an effort to see if the structural distortion seen with the $\mathrm{Pu}$ oxide on goethite $(\mathrm{FeOOH})$ exists with other minerals.

\section{Task C2: Characterization of Pu on Natural Minerals Colloids}

The objective of this task was to determine the form of the Pu found on environmental samples. In FY10 we initially demonstrated that we could use a combination of the SEM and NanoSIMS to image and detect low levels of $\mathrm{Pu}$. We showed that we could detect $\mathrm{Pu}$ on goethite at $0.7 \mathrm{ppm}$. We also initiated a collaboration with Andy Felmy at PNNL, to characterize a series of highly contaminated soil samples collected beneath a Hanford 
crib in an effort to determine how $\mathrm{Pu}$ is associated with the subsurface mineralogy. This project is quite challenging as concentrations are usually below detection limits, but the success will help to better understand how the $\mathrm{Pu}$ has been transported under a given set of geologic conditions.

\section{Hanford Reservation, Washington State}

We received samples from three different depths beneath a crib at the Hanford Reservation. These samples contained approximately 5 grams of sand/silt soils collected at depths $49-64 \mathrm{ft}$ beneath the surface. An overview of the samples and their activity for ${ }^{241} \mathrm{Pu},{ }^{239} \mathrm{Pu}$ and ${ }^{241} \mathrm{Am}$, as measured by gamma spectroscopy, is given in Table $\mathrm{C} 1$.

\section{Table C1. Hanford soil samples}

\begin{tabular}{|llcccc||}
\hline Sample ID & depth & soil (g) & Am-241 (nCi) & Pu-241 (nCi) & Pu-239 (nCi) \\
\hline B1HVC8 & $49-50^{\prime}$ & 5.96 & 152 & below DL & 45 \\
B1HK15 & $63.5-64.5^{\prime}$ & 5.38 & 344 & 1516 & 382 \\
B1HY61 & $>65$, & 5.53 & 125 & 36 & 134 \\
\hline
\end{tabular}

In FY10 several milligrams of contaminated soil were embedded in epoxy, polished, an analyzed by scanning electron microscopy (SEM) and NanoSIMS. Sample B1HK15 and B1HY61 had the highest activity according to gamma spectroscopy measurements (Table $\mathrm{C} 1$ ) and were therefore selected for initial analyses.

For the ion images from Hanford samples B1HK15 and B1HY61, the counts on $m / z 239$ were typically highest on the grain edges and were often, but not always, correlated with Fe (Fig. C5). The analyzed areas with 'hot spots' of $\mathrm{m} / \mathrm{z} 239$ were relocated on a secondary electron microscope for further investigation by energydispersive X-ray analysis (SEM-EDX). Identification of the mineral grains associated with the Pu is on-going. These efforts will help to correlate the counts at $m / z 239$ detected in the NanoSIMS with the different mineral phases.
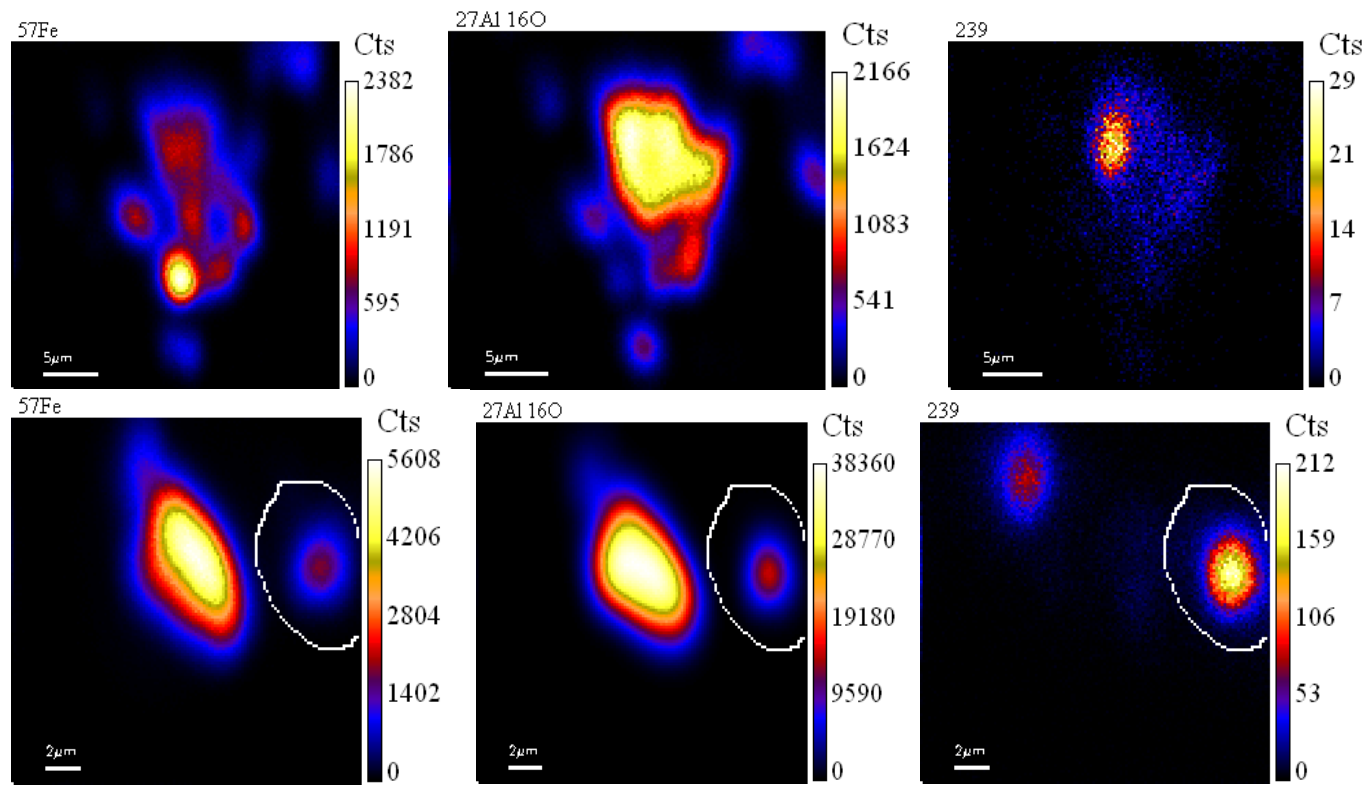

Fig. C5

Elemental maps of 2 different areas containing Hanford soils. 20 $\mathrm{x} 20$ um ion images of ${ }^{57} \mathrm{Fe}$, ${ }^{27} \mathrm{Al}$, and ${ }^{239} \mathrm{Pu}$. 
Although Pu-239 was detected on Hanford soil samples, the relative secondary ion intensities showed a different behavior than what was measured for the goethite+Pu standards described in our FY10 report. More specifically, the intensity of the ${ }^{239} \mathrm{Pu}^{+}$ions was generally higher than the ${ }^{239} \mathrm{PuO}^{+}$ions, which is unusual for sputtering with a primary oxygen beam. Given the very low count rate that was observed on $\mathrm{m} / \mathrm{z} 255$ relative to $\mathrm{m} / \mathrm{z} 239$, the possibility of unresolved mass interferences needs to be taken into account, especially for these mineral samples in which a wide range of elements is present. We are therefore exercising caution in the interpretation of these ion images, and in FY11 are developing and analyzing a new set of plutonium standards using different matrix materials (e.g., clays and quartz) that is more similar to the soil matrix.
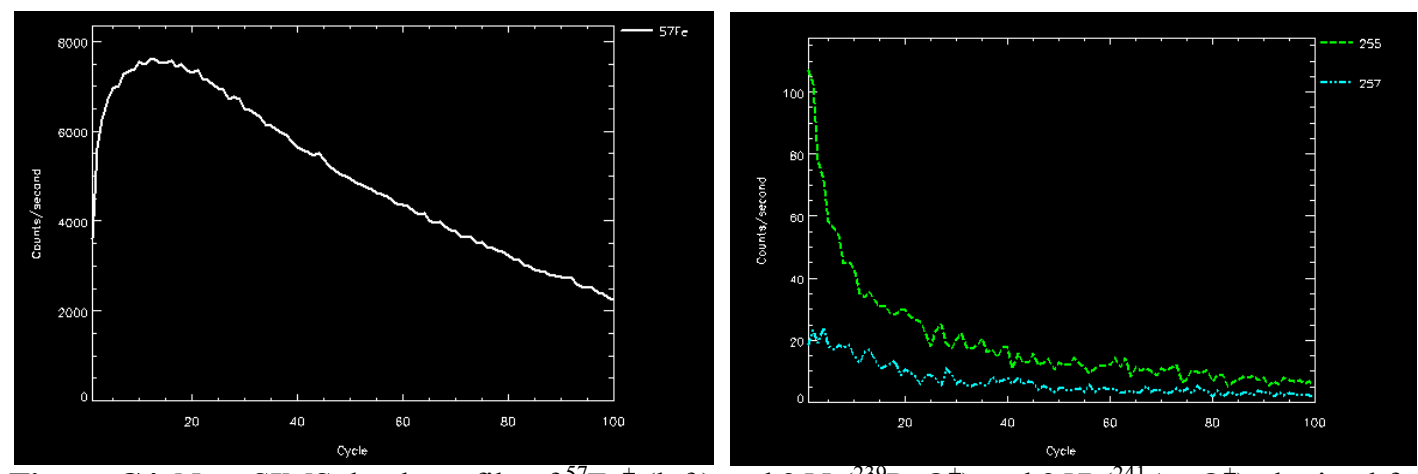

Figure C4. NanoSIMS depth profile of ${ }^{57} \mathrm{Fe}^{+}$(left) and $255\left({ }^{239} \mathrm{PuO}{ }^{+}\right)$and $257\left({ }^{241} \mathrm{AmO}^{+}\right)$obtained from sputtering a mixed $\mathrm{Pu} / \mathrm{Am}$ goethite particle for several hours.

\section{Program Element D: Co-precipitation with Altered Colloids (S. Carroll: lead; H. Mason M., Zavarin and P. Zhao)}

At the NTS, 98\% of the Pu and other actinides deposited in the subsurface as a result of an underground nuclear test are thought to be sequestered by melt glass produced in the nuclear detonation. This Program Element is designed to investigate the $\mathrm{Pu}$ solubility and structure when the $\mathrm{Pu}$ is associated with colloidal silicates and nuclear melt glass from the NTS. Experiments conducted in this element will determine the conditions under which dissolved $\mathrm{Pu}$ concentrations are controlled by isomorphic substitution in secondary phases and those under which they are controlled by $\mathrm{PuO}_{2}$ solubility (even at low concentrations). The hypothesis guiding the effort in Program D is the following:

\section{Colloid formation during primary rock alteration and secondary mineral precipitation can structurally isolate $\mathrm{Pu}$ in colloids at environmental concentrations.}

This Program Element consists of three tasks. Task D1 is designed to model the sorption of Pu at the silica/water interface at environmental concentrations. Given the difficulties in the experimental analysis of $\mathrm{Pu}$ sorption and co-precipitation at environmental concentrations, atomic-scale simulations are essential to clarify the nature of $\mathrm{Pu}$ aqueous speciation, sorption at mineral/water interfaces, and incorporation into the mineral framework. Task $\mathrm{D} 2$ involves using NMR and solution chemistry to probe the structural environment of $\mathrm{Pu}$ with inorganic, organic and microbial colloids. Task D3 is a series of experiments that alter and characterize nuclear melt glass from the NTS.

\section{Task D1: Molecular Scale Simulations}

For FY10 our milestone was to begin molecular-scale simulations taking advantage of advances in algorithms and computing hardware at LLNL that allow for the finite-temperature simulation of simple interfaces that explicitly include a liquid water layer. We have carried out first principles molecular dynamics simulations for the $\alpha-\mathrm{Al}_{2} \mathrm{O}_{3}(0001) /$ water interface, and our findings for the interfacial structure are consistent with synchrotron $\mathrm{X}$-ray scattering experiments (Eng et al., 2000). This work has continued in FY11 and was presented above in Program Element A, Task A3: Ab-initio modeling. 


\section{Task D2: NMR and Solution Chemistry to probe Structural Environment of Pu}

\section{The NMR spectroscopic study of paramagnetic cation sorption as an analogue for Pu sorption}

We have been developing NMR methods, which can be applied to the study of Pu interactions at the silica surface. A key challenge of using NMR spectroscopy to study the chemical structure of $\mathrm{Pu}$ at mineral surfaces is that $\mathrm{Pu}$ and its compounds exhibit paramagnetic electronic ordering which degrades the signal. However, comparing ${ }^{29} \mathrm{Si}\left\{{ }^{1} \mathrm{H}\right\} \mathrm{CP} / \mathrm{MAS}$ NMR spectra of sorption samples to control samples synthesized in the absence of any paramagnetic cations should yield information about how the paramagnetic cations bind to the silica surface. We have investigated the sorption of the paramagnetic cations $\mathrm{Co}^{2+}, \mathrm{Cu}^{2+}$, and $\mathrm{Ni}^{2+}$ to the surface of amorphous silica using ${ }^{29} \mathrm{Si}\left\{{ }_{1}^{1} \mathrm{H}\right\} \mathrm{CP} / \mathrm{MAS}$ NMR spectroscopy. These systems have been chosen to serve as spectroscopic analogues of the Pu system. The ${ }^{29} \mathrm{Si}\left\{{ }^{1} \mathrm{H}\right\} \mathrm{CP} / \mathrm{MAS}$ technique is surface selective since the protons exist only on the surface of the amorphous silica.

In FY11, individual spectra were collected for a control sample, and two Ni sorbed samples are presented in Figure D1. In these spectra we resolve three unique ${ }^{29} \mathrm{Si} /{ }^{1} \mathrm{H}$ environments, which we have labeled $\mathrm{Q}^{2}, \mathrm{Q}^{3}$, and $\mathrm{Q}^{4}$. Of these the $\mathrm{Q}^{2}$ and $\mathrm{Q}^{3}$ sites represent surface silanol sites where the paramagnetic cations can bind and the $\mathrm{Q}^{4}$ site is an internal siloxane. We observe a significant reduction in the overall absolute intensity for all of the paramagnetic sorbed silica samples.
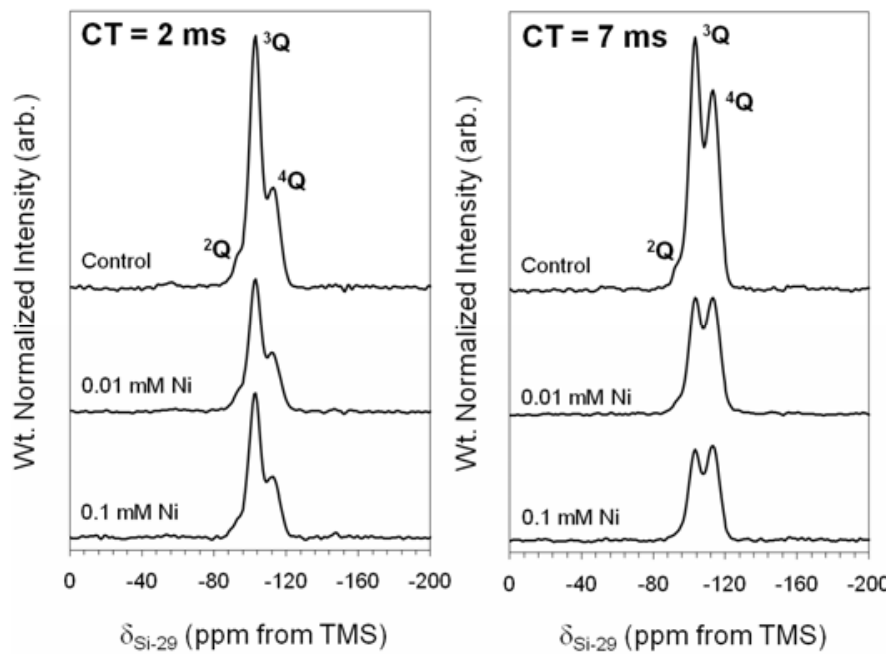

Figure D1. Stacked ${ }^{29} \mathrm{Si}\left\{{ }^{1} \mathrm{H}\right\} \mathrm{CP} / \mathrm{MAS}$ NMR spectra collected at a $\mathrm{CP}$ contact time of $2 \mathrm{~ms}$ (left) and $7 \mathrm{~ms}$ (right) for (top to bottom) a control sample and two samples sorbed with different $\mathrm{Ni}$ concentrations. The spectra are all collected under identical acquisition conditions and are scaled to reflect their sample weight corrected absolute intensity.

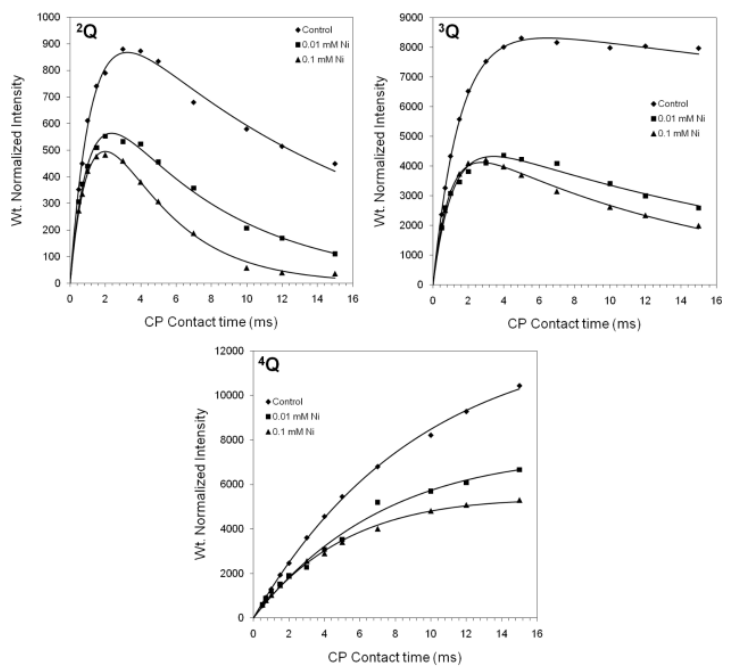

Figure D2. ${ }^{29} \mathrm{Si}\left\{{ }^{1} \mathrm{H}\right\} \mathrm{CP} / \mathrm{MAS}$ kinetics curves produced for the $\mathrm{Q}^{2}, \mathrm{Q}^{3}$, and $\mathrm{Q}^{4}$ silica sites for the control $(\diamond), 0.01 \mathrm{mM} \mathrm{Ni}$ $(\bullet)$, and $0.1 \mathrm{mM} \mathrm{Ni}$ sample ($\bullet)$. Solid lines represent least squares fit to a "classical" CP kinetics model. The data is scaled to reflect the sample weight corrected absolute intensities.

We also collected ${ }^{29} \mathrm{Si}\left\{{ }^{1} \mathrm{H}\right\} \mathrm{CP} / \mathrm{MAS}$ spectra for all samples as a function of the CP contact time and the silica site specific CP kinetics data for each sorption sample (Fig. D2). In all cases, the curves collected for the paramagnet sorbed samples show significant deviation from those of the control samples. However, we note that the rates of the intensity increase for the $\mathrm{Q}^{2}$ and $\mathrm{Q}^{3}$ sites are invariant among the samples indicating that the sorption of the cations has little influence on average $\mathrm{Si}-\mathrm{OH}$ bond lengths. The main differences apparent are the absolute magnitude of the intensity $\left(\mathrm{I}_{0}\right)$ and the decay constant $\left(\mathrm{T}_{1 \rho, \mathrm{H}}\right)$. A systematic decrease is observed in both the $T_{1 \rho, H}$ and $I_{0}$ values with increasing paramagnetic cation concentration. These effects are largely due to the paramagnetic cations perturbing the ${ }^{1} \mathrm{H}$ spin population such that the intensity from the ${ }^{1} \mathrm{H}$ in closest association with the paramagnet species is lost resulting in a reduction of $\mathrm{I}_{0}$, but this paramagnet sufficiently alters the relaxation kinetics resulting in a reduction of $\mathrm{T}_{1 \rho, \mathrm{H}}$. A sample where $\mathrm{Ni}(\mathrm{OH})_{2}$ colloids were physically mixed 
with a control sample was also analyzed and the kinetic data is within experimental uncertainty from that of the pure control sample. These data indicate that the effects observed here must arise from the presence of direct bonds between the paramagnetic species and the silica surface, and not the presence of precipitates. Our results indicate that NMR spectroscopic methods can not only probe the interactions between paramagnetic ions and the amorphous silica surface at relatively low initial concentrations, but can also successfully differentiate between surface sorption and precipitation. In FY12 we will apply these same methods to investigate interactions between $\mathrm{Pu}$ and amorphous silica.

\section{Task D3: Alteration of Pu-Containing Glass}

Long-term alteration experiments of Pu-containing glasses ( 2 year experiments, with 6 month sampling) at 25 to $200 \mathrm{C}$ are underway using large volume $(600 \mathrm{~mL})$ in Titanium Parr bomb vessels. Gram quantities of Pucontaining glasses are being reacted to allow a thorough examination of secondary phases, characterization of $\mathrm{Pu}$ association, and follow-on $\mathrm{Pu}$ stability/desorption experiments. Characterization of $\mathrm{Pu}$ associated with secondary phases will be conducted by a combination of SEM, TEM, and NanoSIMS (e.g. Fig. D3).
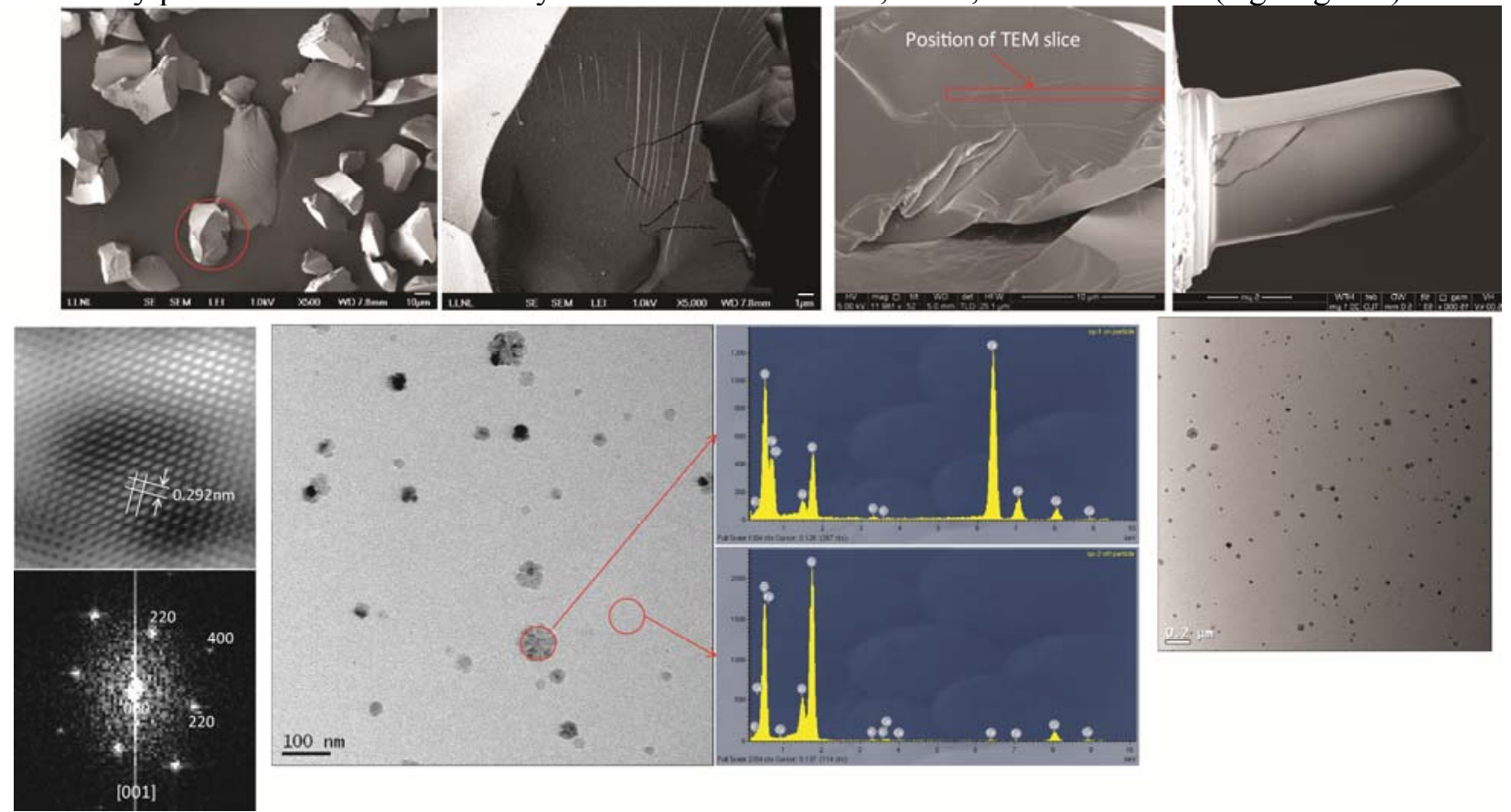

Figure D3. Initial characterization of Pu-containing glasses used in co-precipitation experiments. Unique combination of integrated SEM, FIB, and TEM capabilities used to identify magnetite nanoparticles in Pu-containing glass used in alteration experiments.

\section{Program Element E: Direct and Indirect Microbial Interactions with Pu and Colloids (D. Moser, Lead; J. Fisher)}

Microorganisms are associated with a variety of radioactive materials at DOE sites (Barnhdardt et al., 1980; Francis et al., 1980; Fredrickson et al., 2004) and it is becoming well-known that Pu speciation and solubility are affected by microorganisms (Gilllow et al., 2000; Neu et al., 2005; Panak and Nitsche, 2001). This Program Element tests the hypothesis that:

Environmental microorganisms can impact the mobility of Pu by direct and indirect mechanisms at environmentally relevant concentrations.

Most Pu microbiology to date has been performed on a handful of laboratory strains (Macaskie and Basnakova, 1998; John, 2001; Rusin et al., 1994; Francis, 2007; Panak and Nitsche, 2001) and at relatively high $\mathrm{Pu}$ concentrations (micromolar to millimolar). The general lack of knowledge concerning the 
diversity, biodensity, exopolymer production potential, and direct Pu-reduction capacity of microorganisms at $\mathrm{Pu}$-contaminated DOE sites is a knowledge gap that needs to be filled in order to assure that DOE's longterm stewardship goals are met.

In FY10 we met our milestones in Task E1 of screening a range of dominant microbial physiotypes from the Nevada National Security Site (NNSS, formerly the Nevada Test Site or NTS) despite limited hot well sampling opportunities. Three major objectives were to: identify the Pu-interactive microorganisms from the NNSS, determine if the isolated microorganisms can be grown in the lab, and produce and purify microbial organic matter (in this case extracellular polymeric substances, or EPS) to be used in the ternary sorption experiments with minerals, $\mathrm{Pu}$, and NOM.

\section{Task E1: $\quad$ Survey of Pu-Interactive Microorganisms}

In addition to the direct effects of microorganisms, two indirect microbial processes (ligand production and mineral alteration) could influence Pu mobility at the NTS. It is well known that natural and artificial complexants impact the solubility of $\mathrm{Pu}$ (e.g., Kersting et al., 1999). Microorganisms can produce a variety of such ligands (e.g., siderophores (John, 2001) and extracellular polymeric substances (EPS) (Harper et al., 2008)) or may themselves be viewed as colloids because they fall within the appropriate size range (e.g., $1 \mathrm{~nm}$ to $1 \mathrm{~mm}$ (Lawrence, 1996)). It is also well established that $\mathrm{Pu}$ interacts with mineral colloids (e.g., clays, Fe-oxides) (Kesting et al., 1999, Novikov et al., 2006). Nevertheless, the question of how microbial weathering of these materials impacts actinide sorption remains unaddressed.

In FY10 we conducted both fieldwork and laboratory experiments that provided the starting material and baseline data for experiments conducted in FY11. UGTA field sampling ( 2 wells: ER-EC-11 (clean) and ER20-7 (contaminated)) was limited to the last quarter of FY10. Additional wells: ER-20-8 and BILBY (clean), ER-20-5 \#1 (high contamination), and ER-20-5 \#3 (low contamination) were sampled in FY11 in conjunction with another DOE-funded project ((Moser PI, project ID, \# 0016212). Laboratory experiments in FY2010 included enrichment for a variety of microbial physiotypes from NNSS and initial screening of NNSS organisms for $\mathrm{Pu}$ interaction. We also began the groundwork for examining the role of microbial organic matter that could promote or compete with Pu binding to natural surfaces. The inclusion of two "clean" wells in the FY11 sampling allowed us to estimate the number of subsurface microbes present at these sites by flow cytometry. Flow cytometry provides quantitative data on the number of cells present in a water sample, including the number of cells per milliliter and the fraction of those cells that are viable using two different cell staining methods. This method can only be used for non-radioactive samples, and was thus employed for enumerating cells from BILBY and ER-20-8. The density of cells from these sites was in the range of $10^{4}$ cells $\mathrm{mL}^{-1}$, with viable cells on the order of $10^{3} \mathrm{~mL}^{-1}$.

Archived fluids previously collected from the NTS (water from Tunnel U12N.10) were used to obtain microbial enrichments in FY10. Culturing, isolation, and characterization of bacteria from these samples and from fresh sample collections were performed during FY11. New microbial isolates were obtained from water collected from ER-20-7, and these and previously isolated organisms were identified by their 16S rRNA gene sequences (Fig. E1). The organism selected for production of natural organic matter (NOM) is a Pseudomonas sp. designated EPS1-W. Pseudomonas is a widely distributed genus common to soils and freshwater, and many relatives of our organism have been used previously for production of EPS. Many Psuedomonas spp. were also isolated from the NNSS (Rainier Mesa Tunnels) during previous microbial studies (Haldeman and Amy, 2003).

The major focus of our work in FY11 has been producing the EPS to be used in future experiments (Program Element B). Several methods for extracting and purifying EPS from a pure culture of Pseudomonas EPS1-W were tested and compared for 1) efficiency of EPS removal, 2) total EPS yield (based on TOC analysis), and 3) purity of EPS (e.g., minimization of cell lysis). The final method selected was modified from a recently published method (Cao et al., 2011). Briefly, cells were grown as a biofilm on agar plates for 48 hours, washed from the plate with a saline buffer, and pelleted by centrifugation. Cell washing with both saline buffer and an EDTA-based buffer was employed to remove both loosely and tightly-bound EPS from the cells. EPS was filtered $(0.22 \mu \mathrm{m})$ to remove any cells, concentrated via $3 \mathrm{kD}$ centrifugal filters, then precipitated with ethanol 
overnight. Precipitated EPS was re-suspended with distilled de-ionized water, then dialyzed ( $2 \mathrm{kD})$ for 96 hours to remove any remaining salts and ethanol.

The quantity of EPS produced by each method was measured by TOC analysis conducted at LLNL. The quality of EPS was determined by the presence (or absence) of nucleic acids (an indicator of cell lysis). This analysis compares the spectrophotometric absorbance of EPS samples stained with 4',6-diamidino-2-phenylindole (DAPI), a fluorescent dye that binds to nucleic acids. Nucleic acid analysis was performed by LLNL and showed that the EPS samples contained little to no nucleic acid contamination (statistically the same as the negative control). Flow cytometry was also run on EPS-stripped cells to compare biomass (total numbers) to total viable cells (intact). These numbers were equivalent within the margin of error for replicates of each sample. Aliquots of these cells were plated on agar and grown overnight to confirm viability.

This method appears to yield both a high quantity and a high quality of EPS. Production and purification of EPS will continue, followed by a more complete chemical characterization to determine the structure of the EPS (molecular weight distribution, component sugars, associated proteins, etc.). A target of $1 \mathrm{~g}$ of (dry weight) EPS will be produced and archived for future experiments.

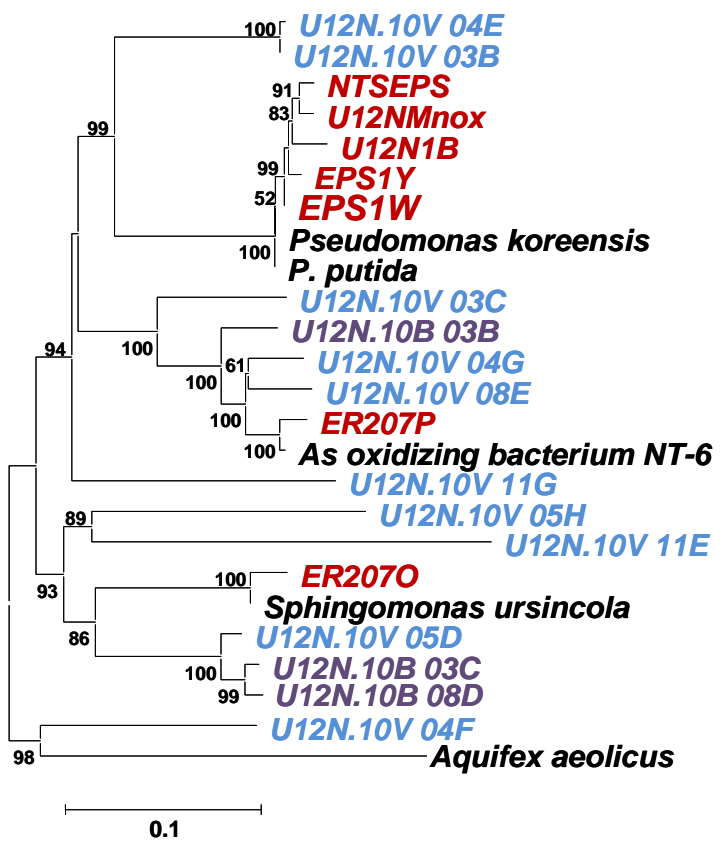

Figure E1. Phylogenetic tree of NNSS isolates from U12N.10 Tunnel and site ER-20-7 based on the 16S rRNA gene. Sequences in red are isolates; sequences in blue and purple are from environmental clone libraries, and sequences in black are characterized reference organisms.

EPS from one of the tested methods (lower yield) was used in a sorption experiment similar to those performed in FY10 with live, whole cells or lysed cells in solution with 10-9 M Pu. In the FY10 experiments, a high percentage (70-90\%) of the Pu that was present sorbed to cells immediately (in $0.25 \mathrm{~h}$ ) suggesting that biological material in the environment would also sorb $\mathrm{Pu}$, even under transport conditions with low residence times/high flow rates. Pu remained sorbed after 24 hours. Lysed cells of Shewanella CN-32 had the highest $\mathrm{K}_{\mathrm{d}}$ and sorbed the greatest percentage of $\mathrm{Pu}$, possibly due to the increased surface area made available by compromised cell membranes. This observation is also important because it shows that cells do not need to take up $\mathrm{Pu}$ into the periplasm or cytoplasm to produce a biosorptive effect. Also notable were the higher $\mathrm{K}_{\mathrm{d}}$ values for treatments with higher EPS contents, suggesting that Pu may sorb primarily to EPS as has been shown for other actinides.

In the FY11 experiment, $\sim 0.01 \mathrm{mg}$ of EPS was mixed with $\mathrm{Pu}$ in a low $\mathrm{pH}(<5)$ solution and placed in Slide-alyzers (self-contained dialysis units), then dialyzed over the course of 48 hours. Over $85 \%$ of Pu was retained 
inside the membrane with the EPS. These experiments will be repeated at more environmentally relevant $\mathrm{pH}$ (7.5-8) at the end of FY11 following production and characterization of EPS.

\section{4.a.ii Scientific Highlights}

Successful measurement of Pu at ultra-trace levels using CAMS. Plutonium-goethite sorption experiments were performed to aqueous concentrations below $5 \times 10^{-17} \mathrm{M}$, equivalent to the detection of $3 \times 10^{6}$ atoms in a $100 \mathrm{~mL}$ sample. This CAMS capability will allow us to readily perform laboratory experiments that cover the range of environmental $\mathrm{Pu}$ concentrations of interest.

Ternary Pu-NOM-gibbsite $\left(\mathrm{AlOH}_{3}\right)$ sorption experiments demonstrated the mobilization of Pu as a result of aqueous complexation over a $\mathrm{pH}$ range of 5-9. The degree of $\mathrm{Pu}$ mobilization by NOM (DFOB $>$ crtric acid $\approx$ fulvic acid $>$ humic acid) reflects the stability of the binary aqueous complexes.

Demonstrated Pu detection using NanoSIMS at concentrations as low as $0.7 \mathrm{ppm} P u$ on goethite. This is well below the concentrations at which Pu nano-colloids were observed by TEM and surpassed expectations outline in the SFA proposal. As a continuation of this work, in FY11 we successfully imaged nanometer-scale Pu distribution on Hanford sediments located 60 feet beneath a disposal crib using the NanoSIMS. Additional work to identity the mineral association of Pu will greatly help us understand how $\mathrm{Pu}$ moves in the subsurface.

Identified Pu nano-colloids lattice distortion when sorbed to goethite resulting in the formation of a bcc, $\mathrm{Pu}_{4} \mathrm{O}_{7}$ structure. This distortion results from an epitaxial growth of colloidal plutonium on goethite and provides new insight into the molecular scale behavior of $\mathrm{Pu}$ and how that may facilitate its transport in the subsurface. Powell at al., 2011 EST45(7) pp 2698-2703. As a continuation of this work, in FY11 we demonstrated that a similar distortion occurs with $\mathrm{Pu}(\mathrm{V})$ surface reduction to $\mathrm{Pu}(\mathrm{IV})$ on goethite.

Applied first-principles, Ab initio, modeling. Showed that in an aqueous environment the planar form of $\mathrm{Pu}(\mathrm{OH})_{4}$ isomer can potentially be stabilized over the tetrahedral form (paper submitted).

\section{4.a.iii Summary of Publications}

Publications were highlighted in each Program Element where appropriate. To summarize, we published 2 papers, 2 have been accepted and 1 is in press. We presented 11 presentations at national meetings (1 invited).

Powell, B.A., Zurong Dai, Mavrik Zavarin, Pihong Zhao, Annie B. Kersting. (2011) Stabilization of Plutonium Nano-Colloids by Epitaxial Distortion on Mineral Surfaces, ES\&T 45 (7), pp 2698-2703

Zhao P., Zavarin M., Leif R., Powell B., Singleton M., Lindvall R., and Kersting, AB. (2011). Mobilization of actinides by dissolved organic compounds at the Nevada Test Site Applied Geochemistry. 26:3 308-318

Tinnacher, R. M.; Zavarin, M.; Powell, B. A.; Kersting, A. B. (2011) Kinetics of Neptunium(V) Sorption and Desorption on Goethite: An Experimental and Modeling Study, Accepted Geochimica et Cosmochimica Acta, .

Kersting, A.B. and Zavarin, M. (2011) Chapter: Colloid Facilitated Transport of Plutonium at the Nevada Test Site, NV, USA. In: Actinide Nanoparticles Research. Ed. Kalmykov, S. and Denecke, M. In press. Springer.

Huang, P., Zavarin, M., and Kersting, A.B. Ab initio electronic structure of $\mathrm{Pu}(\mathrm{OH}) 4$ : Comparison between density functional and multi-reference theories. Submitted, 2011.

Snow, M. et al. Neptunium Sorption to Goethite. LLNL summer student poster session, Aug. 8, 2010 LLNL-POST-448451. 
Zhao, P. et al. Pu Sorption to Goethite at Micromolar to Attomolar Concentrations. Poster Pu Futures-The Science, Sept 19-23, 2010, Keystone CO

Tinnacher, R. M.; Zhao, P.; Williams, R. W.; Zavarin, M., Kersting, A. B. Neptunium-237 Concentrations in Groundwater from Nevada Test Site Wells. Poster Pu Futures: The Science 2010, Keystone, CO, 19-23 Sept. 2010.

Tinnacher, R. M.; Powell, B. A.; Kersting, A. B.; Zavarin, M. A New Approach to Simulate the Kinetics of Metal Desorption from Mineral Surfaces. Talk AGU Fall Meeting, San Francisco, CA, 13-17 Dec. 2010.

Honeyman, B. D.; Tinnacher, R. M. Changes in the Kinetics of Uranium(VI) Sorption Reactions to Mineral Surfaces in the Presence of Fulvic Acid. Poster AGU Fall Meeting, San Francisco, CA, 13-17 Dec. 2010.

Zhao, P. et al. Isotherm of Pu/Goethite System: Linearity and Sorbent Surface Characterization. Poster AGU, San Francisco, Dec. 15-19, 2010

Fisher, J. et al. Microbially Produced Organic Matter and Its Role in Facilitating Pu Transport in the Deep Vadose Zone. Talk AGU, San Francisco, Dec. 15-19, 2010

Kersting; A.B.; Powell, B.A.; Zavain, M.; Zhao, P.; Dai, Z. Structure of plutonium oxide on mineral surfaces. Invited talk. Pacifichem, Dec. 11-17, 2010.

Simpkins, L.; Powell, B. A. Effect of fulvic acid on the sorption of plutonium to minerals, Pacifichem, Dec. $11-17,2010$

Powell, B.A.; Zimmerman, T. N.; Simpkins, L. A.. Modeling plutonium interactions with complex molecules and interfaces. Pacifichem, Dec. 11-17, 2010

Mason, H. E., Maxwell, R. S., and Carroll, S. A. Development of a 29Si\{1H\} CP based surface specific technique for actinide sorption studies. American Chemical Society Fall Meeting, August 28 - September 1st, Denver, CO, 2011.

\section{4.b Future Scientific Goals}

Program Element A: We will complete the Pu sorption experiments on montmorillonite clay that parallel the experiments with goethite and build upon earlier high concentration studies. In FY12 we will begin quantifying desorption rates using goethite and/or montmorillonite in a flow-cell apparatus. Ab initio modeling effort will continue to focus on simulation of monomeric Pu on simple mineral surfaces and in the presence of water.

Program Element B: We will study Pu-EPS and continue to study Pu-fulvic acid aqueous complexation and quantify complexation constants. We will examine the effect of ternary systems on sorption/desorption kinetics with different NOM and Pu.

Program Element $\mathrm{C}$ : We continue our investigation of $\mathrm{Pu}$ epitaxial growth on different mineral surfaces with aluminum analog of goethite (diaspore, a-AlOOH) and groutite $(\mathrm{MnOOH})$. We will continue to evaluate Hanford sediments using NanoSIMS.

Program Element D: Sampling and characterization of secondary minerals produced during long-term meltglass alteration experiments will be conducted. TEM will be employed to identify the location of the Pu on the secondary minerals. Secondary minerals will be isolated and used in flow-cell experiments to characterize desorption behavior. NMR studies will examine Pu interactions with amorphous silica.

Program Element E: Ternary sorption experiments using microbial exudates isolated from the Nevada Test Site contaminated wells will be used in sorption/desorption experiments with Pu at LLNL. We are moving our experimental program to LLNL because DRI is not able to work with radioactive samples and that is required for the next stage of work. See 4.d for more details. We will compare these next experiments with experiments in Program Element B.

\section{4.c New Scientific Results See section 4.a.ii}




\section{4.d. Collaborative Research Activities}

We have two sub-contracts to collaborate with two external research groups. The first is with Brian Powell at Clemson University, SC to work on Program Element B. Details of the work are discussed in section 4.a.i, Program Element B. The second sub-contract is with Duane Moser from the Desert Research Institute, NV to work on Program Element E. Details of the work are discussed in section 4.a.i Program Element E.

Going forward in FY12, we will be conducting the microbial work at LLNL. We will close out the subcontract with DRI but will continue to provide access to the NTS for D. Moser through LLNL's work authorization packages and safety protocols. We have hired a postdoc who is a microbiologist and will be supervised by Dr. Yongqin Jiao, who joined our program last year. He will start in January, 2012 and will be working $1 / 2$ time on our program and $1 / 2$ time on Dr. Jiao's program. We believe this change retains the same level of expertise in microbial systems while allowing us to proceed doing experiments with low doses of radioactivity.

We initiated two unfunded research collaborations to investigate contaminated samples from Hanford with Andy Felmy (PNNL) and Tomsk, Russia with Stepan Kalmykov (Moscow State University. Details and results from these collaborations can be found in Section 4.a.i, Program Element C, Task C2.

We had 2 summer students in FY10. Mathew Snow, who subsequently was awarded a Nuclear Forensics Graduate Fellowship to work with Sue Clark at Washington State. He returned in the summer of FY11 to write up his research results for publication. We have 2 new summer students in FY11. They will both be completing an experimental project on actinide environmental radiochemistry.

\section{Staffing and Budget Summary}

\section{5.a Funding Allocation by Program Element}

\section{5.a.i Present Funding}

Our SFA is currently funded at $1.2 \mathrm{M} / \mathrm{yr}$ for 5 years beginning Oct. 2009. We had approximately $200 \mathrm{~K}$ carry-over in FY11. The amount spent in FY11 is projected to be: 


\begin{tabular}{|c|c|c|c|c|}
\hline Program Element & Costs (K) & LLNL & Effort & Cost $(\mathbf{K})^{*}$ \\
\hline & & Researcher & & \\
\hline Program Element A & 400 & $\overline{\text { Annie Kersting }}$ & $15 \%$ & 100 \\
\hline Program Element B & 150 & Mavrik Zavarin & $60 \%$ & 240 \\
\hline (Subcontract Clemson Univ.) & 120 & & & \\
\hline Program Element C & 180 & Pihong Zhao & $60 \%$ & 195 \\
\hline Program Element D & 215 & Patrick Huang & $50 \%$ & 160 \\
\hline \multirow{6}{*}{$\begin{array}{l}\text { Program Element E } \\
\text { (Subcontract DRI) }\end{array}$} & 160 & Zurong Dai & $20 \%$ & 100 \\
\hline & & Scott Tumey & $10 \%$ & 20 \\
\hline & & Ruth Kips & $50 \%$ & 80 \\
\hline & & Ruth Tinnacher & $75 \%$ & 150 \\
\hline & & James Begg & $75 \%$ & 150 \\
\hline & & Harris Mason & $30 \%$ & 60 \\
\hline Total & $1.2 \mathrm{~K}$ & LLNL effort & & $1.25 \mathrm{~K}^{*}$ \\
\hline
\end{tabular}

*Effort costs for LLNL staff do not include supplies, analytical costs or travel. We expect to have approximately 100K carry-over for FY12 Oct start.

\section{5.b Funding for External Collaborators}

External collaborators are: Brian Powell at Clemson University, SC. He is funded by a sub-contract for $\$ 120 \mathrm{~K} /$ year for work in Program Element B. He completed his milestones. Our second collaborator is Duane Moser from Desert Research Institute, NV. He is funded at $\$ 160 \mathrm{~K} / \mathrm{yr}$ for work in Program Element E. He completed his milestones. The effort with U. Clemson will continue at approximately the same level of funding. The funding with Desert Research Institute will end and experiments using Pu in Program Element $\mathrm{E}$ will continue at LLNL in FY12.

\section{5.c Personnel Actions}

Most of our staff continued on in FY11 from FY10 efforts. This includes 8 staff scientists, 4 postdocs and 1 student at LLNL. Collaborations from 2 other institutions were also initiated that include 2 lead scientists, 1 postdoc and 3 graduate students. As part of our efforts to encourage young investigators and hire new staff, we converted one LLNL postdoc to a flex-term staff scientist in April, 2011. We hired one new postdoc in August, 2010. We currently have an opening for one additional postdoc.

\section{5.d National Laboratory Investments}

The Seaborg Institute covers all of the administrative costs to execute this program, and approximately $10 \%$ of an Administrator's time. In addition, the SEM operational cost is also covered under the Institute's operating budget. Annie Kersting, Director of the Seaborg Institute oversees a summer student program that paid for the cost of one summer student working on this program in FY10.

As an institution, LLNL subsidizes the cost of all postdoc by $25 \%$.

Several pieces of equipment were purchased in FY10 and FY11 by other programs that will directly benefit BER. They are: low energy gamma counter (Canberra), BET (Quantachrome Quadrasorb with low surface area Kr option), XRD and Deltech furnace (glass synthesis applications). All equipment is available for this program. LLNL has committed to refurbishment of Building 151 (the primary location of SFA facilities). 
This will involve laboratory refurbishment and modernization, as well as the purchase of new analytical instruments. As part of this renovation, a new low-level lab will be constructed for use by this SFA.

\section{5.e Capital Equipment}

Capital equipment purchases were not made in FY11. 


\section{References}

Banik, N. L., R. A. Buda, S. Burger, J. V. Kratz, and N. Trautmann (2007), Sorption of tetravalent plutonium and humic substances onto kaolinite, Radiochimica Acta, 95(10), 569-575.

Barnhart B.J., Campbell E.W., Martinez E., Caldwell, and Hallet. (1980) Potential microbial impact on transuranic wastes under conditions expected in the Waste Isolation Pilot Plant (WIPP). In Annual Report. Los Alamos National Laboratory.

Cao, B., Shi, L., Brown, R.N., Xiong, Y., Fredrickson, J.K., Romine, M.F., Marshall, M.J., Lipton, M.S., Beyenal, H. (2011) Extracellular polymeric substances from Shewanella sp. HRCR-1 biofilms: characterization by infrared spectroscopy and proteomics. Environmental Microbiology 13(4): 1018-1031.

Cooper, W. J., R. G. Zika, R. G. Petasne, and J. M. C. Plane (1988), Photochemical formation of H2O2 in natural waters exposed to sunlight, Environ. Sci. Tech., 22, 1156-1160.

Demirkanli D.I, Molz F.J., Kaplan D.I., and Fjeld R.A. (2008) A fully transient model for long-term plutonium transport in the Savannah River Site vadose zone: Root water uptake. Vadose Zone Journal 7(3), 1099-1109.

Eng P.J. et al., (2000) Science 288, 1029

Francis A. J., Dobbs S., and Nine B. J. (1980) Microbial Activity of Trench Leachates from Shallow- Land, Low-Level Radioactive-Waste Disposal Sites. Applied and Environmental Microbiology 40(1), 108-113.

Francis A. J. (2007) Microbial mobilization and immobilization of plutonium. Journal of Alloys andCompounds 444, 500505.

Fredrickson J. K., Zachara J. M., Balkwill D. L., Kennedy D., Li S. M. W., Kostandarithes H. M., Daly M. J., Romine M. F., and Brockman F. J. (2004) Geomicrobiology of high-level nuclear waste contaminated vadose sediments at the Hanford Site, Washington State. Applied and Environmental Microbiology 70(7), 4230-4241.

Gillow J. B., Dunn M., Francis A. J., Lucero D. A., and Papenguth H. W. (2000) The potential of subterranean microbes in facilitating actinide migration at the Grimsel Test Site and Waste Isolation Pilot Plant. Radiochimica Acta 88(9-11), 769-774.

Glynn P. D. (2003) Modeling Np and Pu transport with a surface complexation model and spatially variant sorption capacities: Implications for reactive transport modeling and performance assessments of nuclear waste disposal sites. Computers \& Geosciences 29(3), 331-349.

Haldeman, D.L., and P.S. Amy. (1993) Bacterial heterogeneity in deep subsurface tunnels at Rainier Mesa, Nevada Test Site. Microbial Ecology 25:183-194.

Harper R. M., Kantar C., and Honeyman B. D. (2008) Binding of Pu(IV) to galacturonic acid andextracellular polymeric substances (EPS) from Shewanella Putrefaciens, Chlostridium sp. andPseudomonas fluorescens. Radiochimica Acta 96, 753-762.

John S. G., Christy E. Ruggiero, Larry E. Hersman, Chang-Shung Tung, and Mary P. Neu. (2001) Siderophore mediated plutonium accumulation by Microbacterium flavescens (JG-9). Environmental Science \& Technology 35, 2942-2948.

Kaplan, D.I., Powell B.A., Demirkanli D.I., Fjeld R.A., Molz F.J., Serkiz S.M., and Coates J.T. (2004) Influence of oxidation states on plutonium mobility during long-term transport through an unsaturated subsurface environment. Environmental Science \& Technology. 38(19), 5053-5058.

Kaplan, D.I.. Powell B.A., Gumapas L., Coates J.T., Fjeld R. A., and Diprete D.Pl (2006) Influence of pH on plutonium desorption/solubilization from sediment. Environmental Science \& Technology 40(19), 5937-5942.

Kersting A. B., Efurd D. W., Finnegan D. L., Rokop D. J., Smith D. K., and Thompson J. L. (1999) Migration of plutonium in ground water at the Nevada Test Site. Nature 397(6714), 56-59.

Lawrence J. R. H. M. J. (1996) Transport of bacteria through geologic media (review). Can. J. Microbiol. 42, 410 - 422.

Macaskie L. E. and Basnakova G. (1998) Microbially enhanced chemisorption of heavy metals: A method for the bioremediation of solutions containing long lived isotopes of neptunium and plutonium. Environmental Science \& Technology 32(1), 184-187.

Morgenstern, A. and Choppin, G.R., 1999. Kinetics of the reduction of $\mathrm{Pu}(\mathrm{V}) \mathrm{O}_{2}{ }^{+}$by hydrogen peroxide. Radiochimica Acta 86, 109-113.

Mosey, N.J.; Liao, P., and Carter, E.A. (2008). Rotationally invariant ab initio evaluation of Coulomb and exchange parameters for DFT $+\mathrm{U}$ calculation. J. Chem. Phys. 129, 01410

Neck V. and Kim, JL (2001). Solubility and hydrolysis of tetravalent actinides. Radiochim Acta. 89: 1-16. 
Neck V., Altmajer M., Seibert A., Yun J.I., arquardt C.M., and Fanghanel T. (2007) Solubility and redox reactions of $\mathrm{Pu}(\mathrm{IV})$ hydrous oxide: Evidence for the formation of PuO2+X (s, hyd.) Radiochimica Acta 95(4), 193-207.

Neu M. P., Icopini G. A., and Boukhalfa H. (2005) Plutonium speciation affected by environma2001)ental bacteria. Radiochimica Acta 93(11), 705-714.

Novikov, A.P., Kalmykov, S.N., Utsunomiya, S., Ewing, R.C., Horreard, F., Merkulov, A., Clark, S.B., Tkachev, V.V., Myasoedov, B. F. Colloid transport of plutonium in the far-field of the Mayak Production Association, Russia, Science 314, 638 (2006).

Panak P. J. and Nitsche H. (2001) Interaction of aerobic soil bacteria with plutonium(VI). Radiochimica Acta 89(8), 499504.

Pettine, M. and Millero, F.J., 2000. Effect of metals on the oxidation of As(III) with $\mathrm{H}_{2} \mathrm{O}_{2}$. Marine Chemistry 70, 223-234

Pickett D.A. (2005) Approach to assessing the potential effects of colloidal radionuclide transport on nuclear waste repository performance. Nuclear Science and Engineering 151(1), 114-120.

Powell, B. A., R. A. Fjeld, D. I. Kaplan, J. T. Coates, and S. M. Serkiz (2005), Pu(V)O2+ adsorption and reduction by synthetic hematite and goethite, Environmental Science \& Technology, 39(7), 2107-2114.

Powell, B. A., R. A. Fjeld, D. I. Kaplan, J. T. Coates, and S. M. Serkiz (2004), Pu(V)O2+ adsorption and reduction by synthetic magnetite (Fe3O4), Environmental Science \& Technology, 38(22), 6016-6024.

Powell, B. A., et al. (2006), Plutonium oxidation and subsequent reduction by Mn(IV) minerals in Yucca Mountain tuff, Environmental Science \& Technology, 40(11), 3508-3514.

Powell, B. A., Fjeld, R. A., Coates, J. T. , Kaplan, D. I., Serkiz, S. M. "Plutonium Oxidation State Geochemistry in the SRS Subsurface Environment (U)," WSRC-TR-2003-00035, Westinghouse Savannah River Company, U.S. D.O.E. Savannah River Site, December 2002.

Powell B. A., Kersting A. B., Zavarin M., and Zhao P. "Development of a Composite Non-Electrostatic Surface Complexation Model Describing Plutonium Sorption to Aluminosilicates" Lawrence Livermore National Laboratory, LLNL-TR-408276, 2008.

Powell, B.A., Zurong Dai, Mavrik Zavarin, Pihong Zhao, Annie B. Kersting. (2011) Stabilization of Plutonium NanoColloids by Epitaxial Distortion on Mineral Surfaces, ES\&T 45 (7), pp 2698-2703

Rusin P. A., Quintana L., Brainard J. R., Strietelmeier B. A., Tait C. D., Ekberg S. A., Palmer P. D.,Newton T. W., and Clark D. L. (1994) Solubilization of Plutonium Hydrous Oxide by Iron-Reducing Bacteria. Environmental Science \& Technology 28(9), 1686-1690.

Soderholm, L., Almond P.M., Skanthakumar S., Wilson, R.R., and Burns, P.C. (2008) The structure of the plutonium oxide nanocluster Angewandte Chemie-International Edition 47(2), 298-302.

Tien N.C. and Jen C.P. (2007) Analytical modeling for colloid-facilitated transport of N-member radionuclide chains in the fractured rock. Nuclear Science and Techniques 18(6), 336-343.

Tinnacher, R. M. and Honeyman, B. D., 2007. A new method to radiolabel natural organic matter by chemical reduction with tritiated sodium borohydride. Environmental Science and Technology 41, 6776-6782

U.S. Dept. Energy, (2007) Basic research needs for geosciences; facilitating $21^{\text {st }}$ centrury energy systems. Report from the workshop Feb. 21-23, 2007, pp. 186

Zavarin, M., B. A. Powell, M. Bourbin, P. Zhao, and A. B. Kersting (submitted), Np(V) and Pu(V) Sorption to Montmorillonite as a Function of Ionic Strength, pH, and Time, Environ. Sci. Tech.

Zika, R. G., J. W. Moffett, R. G. Petasne, W. J. Cooper, and E. S. Saltzman (1985), Spatial and temporal variations of hydrogen peroxide in Gulf of Mexico waters, Geochemica et Cosmochimica Acta, 49, 1173-1184.

Zimmerman, T. N. "Plutonium humic acid stability constant determination and subsequent studies examining sorption in the ternary Pu(IV)-humic acid-gibbsite system" M.S. Thesis, Clemson University, 2010.

This work performed under the auspices of the U.S. Department of Energy by Lawrence Livermore National Laboratory under Contract DE-AC52-07NA27344 